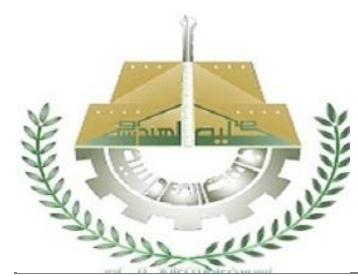

\title{
STUDY THE EFFAECT OF TWEEN 80 ON CLTHRATE HYDRATE FORMATION BEHAVIOR FOR R-134A
}

\author{
Shurooq T. AL-Hemeri \\ Department of Chemical Engineering, University of Technology, Baghdad, Iraq. \\ E-mail: 80024@uotechnology.edu.iq \\ Riyadh S. AL-Mukhtar \\ Department of Chemical Engineering, University of Technology, Baghdad, Iraq. \\ E-mail:rnsa1962@yahoo.com

\begin{abstract}
Mustafa S. Mohammed
Department of Chemical Engineering, University of Technology, Baghdad, Iraq. E-mail:080549@student.uotechnology.edu.iq
\end{abstract}

Abstract: :Clathrate hydrates are complex molecules formed by the contact between water and gas at high pressure and low temperatures. One of the important aims of gas hydrate technology is to enhance the formation of hydrate and reduction the induction time for clathrate formation. Effect of the different promoters (nonionic surfactant Tween80) on R-134a gas hydrate formation has been investigated in the isochoric system experiment. It is noted that the surfactants have a significant effect of increasing the speed of nucleation as well as improving the growth of hydrate. In the experiment, the effect of Tween 80 surfactant was studied to determine its effect on the composition and cooling capacity of 134 hydrates. From kinetic models, many objective functions such as the amount of gas consumed $(\Delta \mathrm{n})$, the growth rate $(\mathrm{r}(\mathrm{t}))$, the apparent rate constant $\left(\mathrm{K}_{\mathrm{app}}\right)$ and conversion of the water to hydrate were obtined. The improvement of hydrate growth is marked by the addition of surfactants, which in turn increase the solubility of hydrate gas and reduce the contact angle. In addition, surfactants positively the contact with the gas through the increase of the gas diffusion in the water and this increases the rate of formation of hydrate. Best value achieved at a surfactant concentration of $100 \mathrm{ppm}$ with maximum gas consumed amount $(0.16 \mathrm{~mol})$ and less indction time $32 \mathrm{~min}$.

Keywords: Key words: Clathrate; gas hydrate; surfactant; refrigerant; thermodynamics model 


\section{NOMENCLATURE}

\begin{tabular}{|c|c|c|}
\hline symbol & Description & $\underline{\text { unit }}$ \\
\hline $\mathrm{a}$ & Parameters of EoS & $\mathrm{MPa} .(\mathrm{L} / \mathrm{mol})^{2}$ \\
\hline $\mathrm{b}$ & Parameters of EoS & $(\mathrm{L} / \mathrm{mol})$ \\
\hline $\mathrm{C}$ & Langmuir constant of cavities & {$[-]$} \\
\hline$f$ & Fugacity of the gas component & $\mathrm{MPa}$ \\
\hline $\mathrm{K}_{\mathrm{app}}$ & Rate constant of hydrate reaction & $\mathrm{Mol} /(\min . \mathrm{pa})$ \\
\hline $\mathrm{n}$ & number of water mol & mol \\
\hline $\mathrm{P}$ & Pressure & Bar \\
\hline q & Parameters of EoS & {$[-]$} \\
\hline $\mathrm{r}$ & Parameters of EoS & {$[-]$} \\
\hline $\mathrm{R}$ & Universal ideal gas constant & $\mathrm{m}^{3} \cdot \mathrm{Pa} /(\mathrm{mol} \cdot \mathrm{K})$ \\
\hline $\mathrm{T}$ & Temperature & $\mathrm{K}$ or ${ }^{0} \mathrm{C}$ \\
\hline $\mathrm{t}$ & Time & minute \\
\hline$t_{\text {ind }}$ & Induction time & minute \\
\hline $\mathrm{V}$ & Volume & $\mathrm{m}^{3}$ \\
\hline $\mathrm{V}_{\text {cell }}$ & Volume of the cell & $\mathrm{m}^{3}$ \\
\hline $\mathbf{v}_{\mathbf{W}}^{\mathbf{L}}$ & Molar volume & $\mathrm{m}^{3} / \mathrm{mol}$ \\
\hline$v_{W}^{M T}$ & Volume of the empty hydrate lattice & $\mathrm{m}^{3} / \mathrm{mol}$ \\
\hline $\mathrm{Z}$ & Compressibility factor & {$[-]$} \\
\hline $\mathrm{SC}$ & Storage capacity & $\mathrm{V} / \mathrm{V}$ \\
\hline $\mathrm{T}_{\mathrm{STP}}$ & Temperature at stander condition & $\mathrm{K}$ or ${ }^{0} \mathrm{C}$ \\
\hline$P_{\text {STP }}$ & Pressure at stander condition & Bar \\
\hline INTROD & & \\
\hline
\end{tabular}

A clathrate is a complex molecule formed by the contact between gas and water at high pressure and low temperatures (Sloan,2008). The cavities within hydrate formation are formed by the hydrogen bonds which occupied by the gas molecules that are the guest molecules (Clark,2001).clathrate technology is most useful in industrial application such as desalination process, gas supply, separation of greenhouse gases, Food engineering etc. 


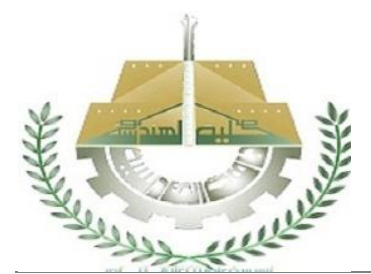

Enhancing the formation of hydrate and the tendency to reduce the induction time needed to form hydrates is one of the main objectives of gas hydrate technology. Induction time is one of the most important parameters used to characterize hydrate Nucleation, This time elapsed to form water and gas groups and their growth towards a stable nucleus with critical size known as the nucleation stage.

The induction time can be expressed by the relationship between the pressure-time of the system in which the gas hydrates are formed as shown in figure (1). The initial pressure drop from $\mathrm{P}_{0}$ to $\mathrm{P}_{\text {sol }}$ caused by dissolution of gas in the liquid aqueous phase. At a steady-state conditions, the pressure stable until formation at which a sudden pressure drop is gas hydrate starts formation. The process of gas consumption continues to leading to low pressure until it reaches a stage where the hydrate is not formed (Sabil, K. M.,2009). The induction time is calculated as:

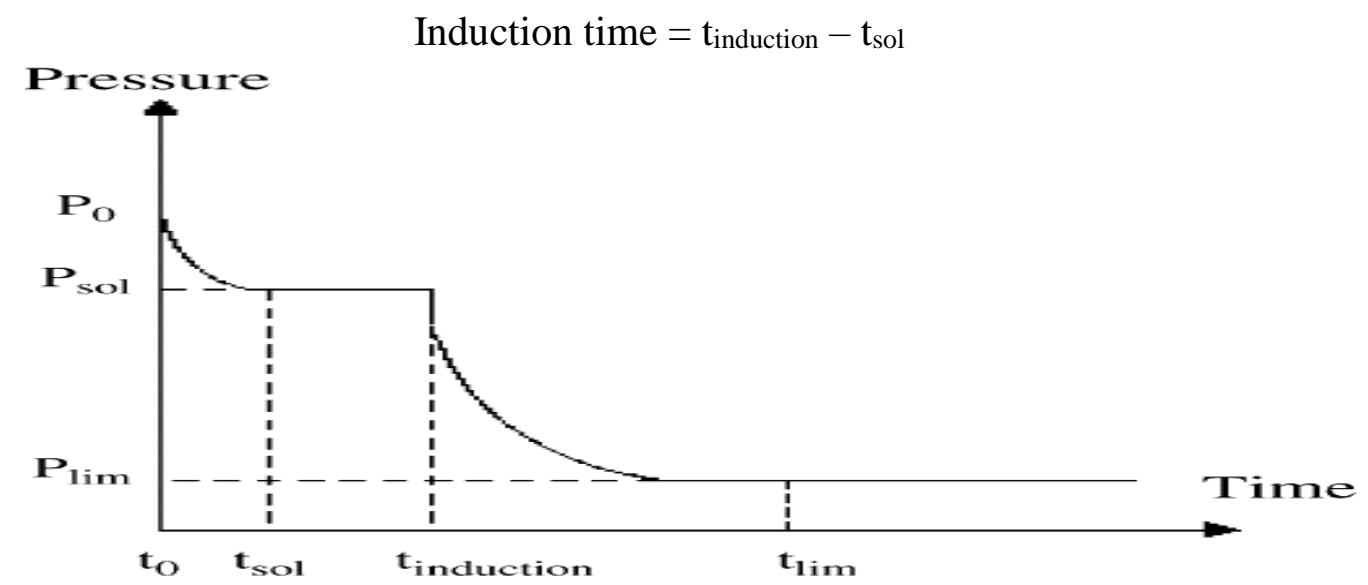

Figure 1. Typical pressure-time-temperature plot obtained during a hydrate formation at constant volume (Sabil, K. M.,2009).

The enhancement of hydrate formation or reducing of induction time for clathrate formation is not easy to achieve because of the volume of hydrate formation layer and the induction time depends on factors such as promoter choice, guest choice, initial pressure, temperature and concentration of promoter. Slow formation of gas hydrate has been a critical problem hindering of gas application (Kalogeraks,1993). Scientists have revealed the advancement impact of a few added substances on the formation of gas hydrate and hydrate gas content. One of the techniques for enhancing the hydrate formation increases the interface accessible for the reaction of hydrate (Han,2002). This can be done effectively by different methods such as mixing water and gas, spraying the water with gas, or by immersing a porous medium in water (Go Y,2002). Another system is the use of synthetic additives, which includes thermodynamic hydration promoters, or motor hydrate promoters, and generally surfactants. Add surfactant enhancing the hydrate formation by increasing the interface accessible for the hydrate reaction (Kang,2001). The surfactants are made up of hydrophobic particles and hydrophilic particles where they show an admiration for polar and 


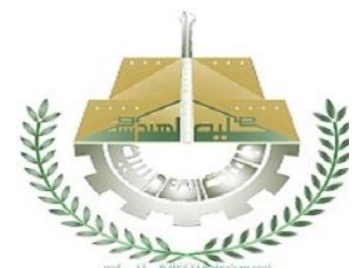

JOURNAL OF AL-QADISIYAH FOR

ENGINEERING SCIENCE

non-polar materials, which are critical factors in the growth rate of hydrates as shown in figure (2) (Kumar,2013).
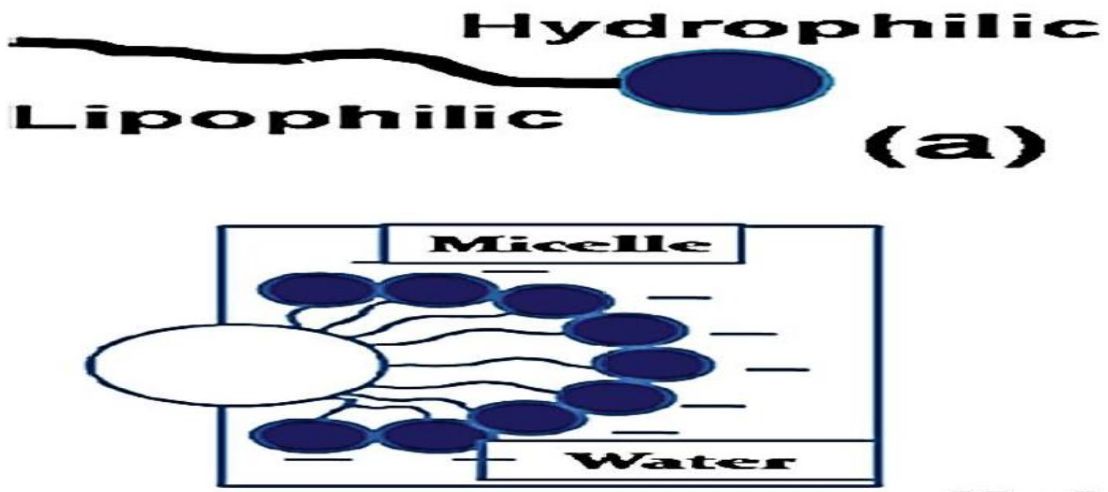

Figure 2. (a) A surfactant molecule with the hydrophilic particles and lipophilic particles groups and (b) formation of micelle in aqueous solution media through association of surfactant molecules(Kumar,2013).

The spread of the surfactant is from the large phase towards the interface which leads to the change of the contact point between the phases and the solid surface, which in turn leads to a change in the charge and viscosity of the surface (Shah,1997).

The atoms of the Surfactants form different forms when they reach the appropriate concentrations and called these structures (micelles) and have different orientations and shapes (circular, pole like micelles, multilayer structures) (Kumar,2015). The Surfactants plays an important role in enhancing hydrate formation especially in industries where arranging micelle is one of the basic requirements that showed in figure (3) (Suradkar,2006). 

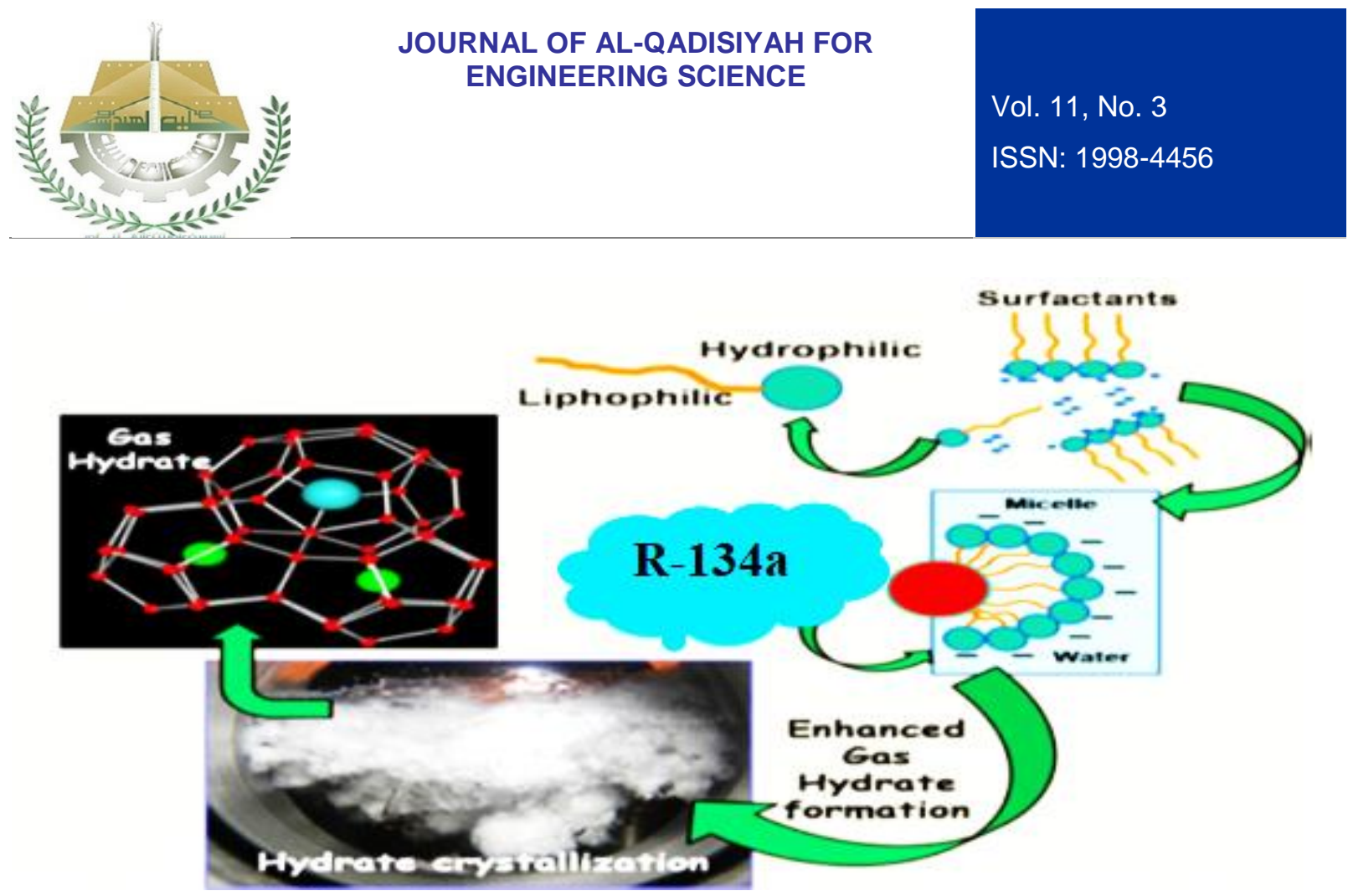

Figure 3. Mechanism of hydrate formation (Kumar,2013).

Several authors reported that adding of surfactant Tween 80 as a promoter of the liquid water and gas guest produces clathrate hydrate utilization of surfactants in gas hydrate-related investigations was continuous since the mid-1990s (Peytavy,1998). The surfactant has been accounted for that the viability of these surfactants for promoting kinetics are system particular (Lim,2013). Tween80 is a polyethoxyl derivative of oleic acid and sorbitan, a water-soluble yellow liquid that is often used in foods. The polyethers are the hydrophilic group and are also known as polyoxyethylene, ethylene oxide estimated polymers (Zhang,2003).

Kalogerakis in 1993 was explained that the behavior of the inhibitor of the surfactant and found that the procedure can be promoted with a little concentration of the surfactant. Zhong and Rogers in $\mathbf{2 0 0 0}$ demonstrated that the rate of gas hydrate formation could be increased by increasing the concentration of sodium dodecyl (SDS) above the primary micelle concentration. Gou in 2002 was explored the calcium hypochlorite impact on the limit of methane capacity and methane hydrate formation rate. Kumar in 2013 studied the three types of surfactant (ionic, cationic, and non-ionic) for their effect on the hydrate formation of carbon dioxide; He noted that the best promoting in hydrate formation and reduction of induction time is (SDS). Nonionic surfactant (Tween-80) was observed on the cationic surfactant.

Zhang et.al. in $\mathbf{2 0 0 8}$ showed solubilization of surfactants produces supersaturated gas molecules, which promotes the mass transfer from a bulk phase to hydrates and provides the driving force for the complexation between host molecules (water) and guest molecules in a gas hydrate formation process and when most of the gas molecules are bound to form clusters with water molecules, which promotes the formation of crystal nuclei of gas hydrates. Al-Mukhtar et la in 2018 studied 


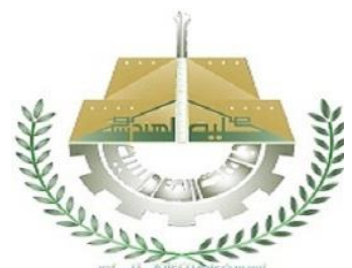

kinetics dissociation for the binary system (water-R-134a) system and for ternary salts $(\mathrm{NaCl}, \mathrm{KBr}$, and $\mathrm{NaF}$ ) system at different concentrations $(0.09,0.17,0.26) \mathrm{mol} / \mathrm{Kg}$ in the isochoric cell. They used Claperyon equation to estimate dissociation heat for the systems with Peng-Robinson - PRSV equation applied for gas compressibility factor $\mathrm{Z}$. They concluded that dissociation heat increased when salt concentration increased. The $\mathrm{NaCl}$ salt with high concentration gave the highest value among the other salt in the study.

In this study, growth rate, induction time, gas consumed, apparent rat constant, storage capacities and conversion of water to hydrate of the hydrates formed in presence of nonionic surfactant (Tween 80) were investigated. The aim has been to find the best concentration of surfactant which achieves best values.

\section{EXPERIMENTAL}

\subsection{MATERIALS}

Refrigerant gas (R-134a) (Frisco, Belgium) with a high purity equal to $99 \%$ was utilized to form a hydrate with distilled water. In experiments, Surfactant was used was Very soluble Tween 80 (Central drug house, India) with chemical formula $\mathrm{C}_{32} \mathrm{H}_{60} \mathrm{O}_{10}$, density (1.06-1.09) $\mathrm{g} / \mathrm{mL}$ and viscosity (300-500) centistokes at $25^{\circ} \mathrm{C}$.

\subsection{APPARATUS}

Figure (4) shows the experimental schematic diagram that used in this study. The most important part in the system is the glass cell with a total volume of $1500 \mathrm{~cm}^{3}$ and having internal diameter of $14 \mathrm{~cm}$ and height of $14.5 \mathrm{~cm}$, the cell was equipped with a magnetic stirrer. A thermocouple type $\mathrm{k}$ with a division scale of $0.1 \mathrm{~K}$ and a digital pressure gauge with a division scale of 0.005 bar were to measure the temperature and pressure. The cell connected to the system through pipes and controlled by a valve for gas injection, water input, and drain valve. The cell surrounded by transparency plastic vessel as heat jacket to maintain the temperature inside the cell, cooling water supplied from bath type Julabo F10-VC was used contains a cooling medium made of ethylene glycol/water with ratio about (1/3) by vol.. The temperature of the medium is adjusted by the controllable circulator. 

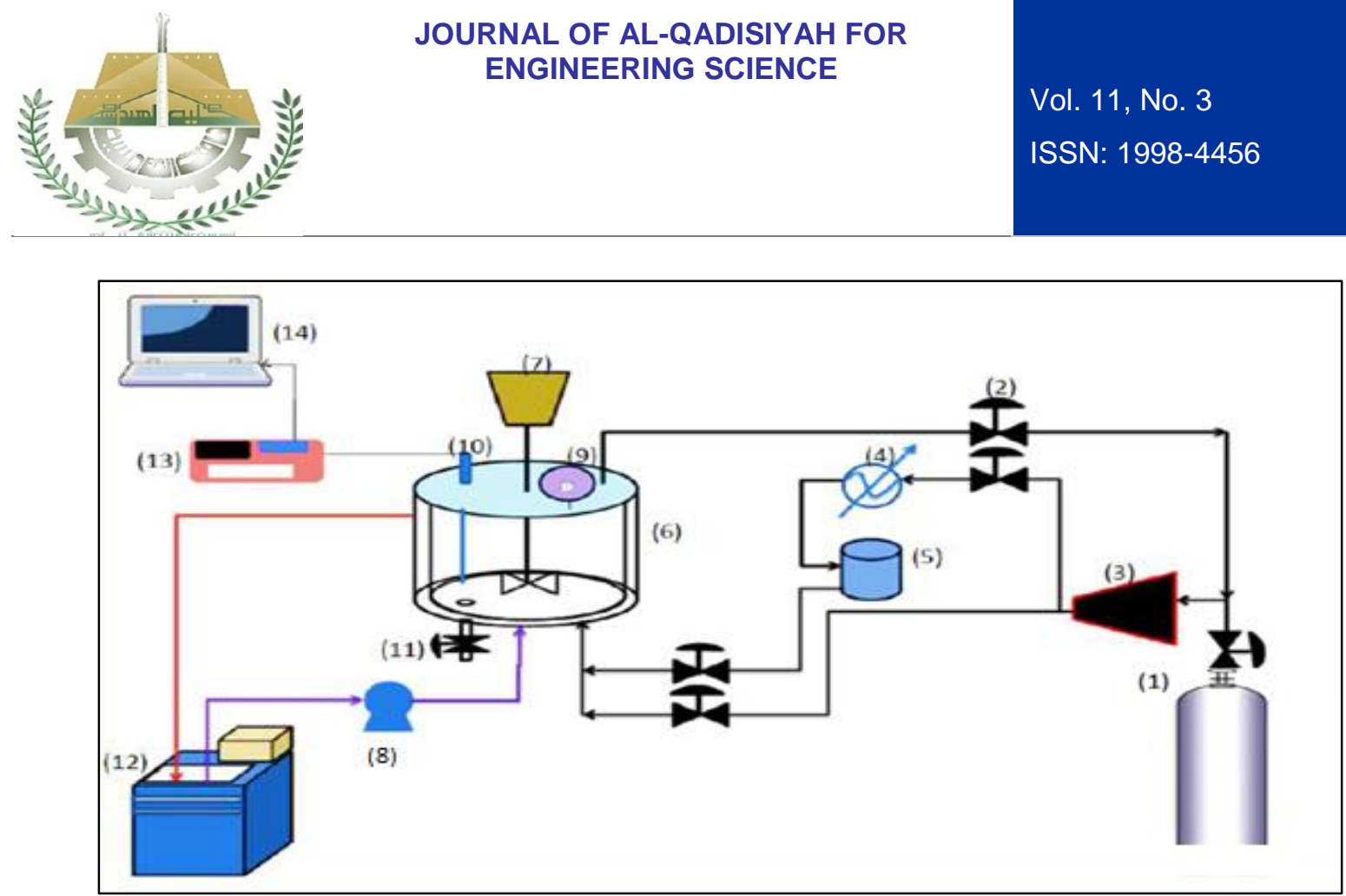

Figure.4 (1) gas cylinder; (2) needle valve; (3) gas compressor; (4)condenser; (5) accumulator of gas; (6) Experimental cell; (7) magnetic stirrer; ; (8) water pump; (9) digital pressure gauges; (10) temperature sensor; (11) valve drain; (12) chiller; (13) interface system; (14) computer.

\subsection{EXPERIMENTAL METHOD}

The constant volume (isochoric) system search strategy was utilized to investigate hydrate formation in this study (Al-Mukhtar, 2018). At to start, distilled water was used to wash the cell and after that washed with acetone to flush the cell. Washed water and acetone lingering were depleted. The cell was emptied to vacuum pressure for a time of $30 \mathrm{~min}$ to guarantee that there were no traces of contamination. The air is evacuated from the reactor using the compressor after feeding of $200 \mathrm{ml}$ (13\% vol of the cell)of water solution mixture inside the cell. A specific measure of R-134a was acquainted of the cell ( $86 \%$ vol of the cell) with achieving the coveted pressure of $0.45 \mathrm{MPa}(4.5 \mathrm{bar})$ at a temperature of $313.15 \mathrm{~K}\left(10{ }^{0} \mathrm{C}\right)$. The mixer was rotates at $250 \mathrm{rpm}$ after the gas pressurized to the cell is completed. The pressure of cell reducing consistently because of hydrate formation until the point when achieving the steady state condition. The stirring speed is set at $250 \mathrm{rpm}$ and initial temperature and pressure at $10{ }^{\circ} \mathrm{C}$ and 4.5 bar respectively with select nonionic surfactant (Tween 80) at different concentrations 0, 25, 50, 75 and 100 ppm. Hydrates are separated by water discharge (non-converted to hydrates) by pressure inside the cell and thus the hydrate is extracted.

\section{THERMODYNAMICS MODEL}

\subsection{GAS CONSUMED}

The moles of the hydrate former consumed throughout the formation of hydrate are obtained by applying the real gas law as follows: 


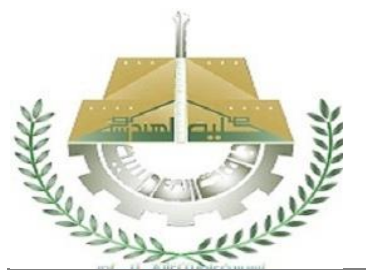

$$
\Delta \mathrm{n}_{\mathrm{H}}=\mathrm{n}_{\mathrm{g}, 0}-\mathrm{n}_{\mathrm{g}, \mathrm{t}}=\left(\frac{P V}{Z R T}\right)_{0}-\left(\frac{P V}{Z R T}\right)_{\mathrm{t}}
$$

The "0" Subscripts refer to the initial conditions where " $t$ " refers to conditions at time, $t$, of the system, $\mathrm{P}$ pressure and $\mathrm{T}$ temperature at the phase equilibrium state, $\mathrm{R}$ was the universal gas constant, and Z was the gas compressibility determined by the Pitzer's correlation (Smith,2001):

$$
\mathrm{Z}=1+\mathrm{B}^{0} \frac{P r}{T r}+\omega \mathrm{B}^{1} \frac{P r}{T r}
$$

Where

$$
\mathrm{B}^{0}=0.083-\frac{0.442}{T_{r}^{1.6}}
$$

And

$$
\mathrm{B}^{1}=0.139-\frac{0.442}{T_{r}^{4.2}}
$$

The hydrate number (number of water molecules) is identified by the partial filling the large and small cavities. The simple hydrate number is calculated $\mathrm{V}_{\mathrm{RWt}}$ is the reacted water's volume (Sloan,2008):

$$
\mathrm{M}=\frac{136}{\left(8 \theta_{S}+16 \theta_{L}\right)}
$$

where $\theta_{\mathrm{S}}$ and $\theta_{\mathrm{L}}$ are is the fraction of linked large and small cavities occupied by guest molecules respectively, as follows (Sloan,2008):

$$
\theta_{\mathrm{i}}=\frac{\left(C_{i} \times f_{i}\right)}{1+\left(C_{i} \times f_{i}\right)}
$$

$\mathrm{C}_{\mathrm{i}}$ is the Langmuir constant for large cavities and small cavities for R134a hydrate. Where $\mathrm{f}_{\mathrm{i}}$ is the fugacity of (R134a) gas which calculates by the apply equation of state (Peng-Robinson) (Robinson,1976). The Langmuir constant of R-134a Ci is formulated as follows(J.Munck,1988):

$$
\mathrm{Ci}=\frac{A i}{T} \exp \left(\frac{B i}{T}\right)
$$

where $\mathrm{Ai}$ and $\mathrm{Bi}$ are constants with values 0.00575 and 4908 for large cavities respectively and $\mathrm{Cs}$ equal to zero for (R134a) gas (P.T.Ngema,2016). 
The gas hydrate volume is not like the aqueous solution volume, To estimate the volume of R134a gas hydrate inside a cell the next equation used:

$$
\mathrm{V}_{\mathrm{t}}=\mathrm{V}_{\text {cell }}-\mathrm{Vs}_{0}+\mathrm{V}_{\mathrm{RWt}}-\mathrm{V}_{\mathrm{HS}}
$$

where $\mathrm{V}_{\text {cell }}$ is the cell volume with value equal $1500 \mathrm{~cm}^{3} ; \mathrm{Vs}_{0}$ is the initial aqueous solution volume with value equal $200 \mathrm{~cm}^{3} ; \mathrm{V}_{\mathrm{Ht}}$ is the produced hydrate's volume and $\mathrm{V}_{\mathrm{RWt}}$ is the reacted water's volume which calculated by using the following equation:

$$
\mathrm{V}_{\mathrm{RWt}}=\mathrm{M} \times \Delta \mathrm{n}_{\mathrm{H}} \times \mathrm{V}_{\mathrm{w}}^{\mathrm{L}}
$$

Where $v_{\mathrm{W}}^{\mathrm{L}}$ displays the molar volume of water that may calculate by the next relation (J.B.Klauda,2000):

$$
\begin{aligned}
\mathrm{v}_{\mathrm{W}}^{\mathrm{L}}= & 18.015 \times\left[1-1.0001 \times 10^{-2}+1.3339 \times 10^{-4}(1.8(T-273.15)+5.50654 \times\right. \\
& \left.10^{-7}(1.8(\mathrm{~T}-273.15)+32)^{2}\right] \times 10^{-3}
\end{aligned}
$$

The hydrate molar volume, $\mathrm{V}_{\mathrm{Ht}}$, can be estimated by the next equation:

$$
\mathrm{V}_{\mathrm{Ht}}=\mathrm{M} \times \Delta \mathrm{n}_{\mathrm{H}} \times \mathrm{V}_{\mathrm{w}}^{\mathrm{MT}}
$$

The gas hydrate molar volume can be assumed equal to the empty hydrate lattice molar volume.

Klauda and Sandler presented the $\mathrm{v}_{\mathrm{W}}^{\mathrm{MT}}$ is the volume occupied by empty hydrate lattice (in $\mathrm{K}$ and $\mathrm{m} 3 / \mathrm{kmol}$ ) as a function of temperature and pressure by following equation (J.B.Klauda,2000):

$$
\begin{aligned}
\mathrm{V}_{\mathrm{W}}^{\mathrm{MT}}= & \left(17.13+2.249 \times 10^{-5} \times \mathrm{T}+2.013 \times 10^{-} 6 \times \mathrm{T}^{2} \times \frac{10^{-30} N_{A}}{136}-8.006 \times 10^{-9} \times \mathrm{P}+\right. \\
& \left.5.448 \times 10^{-12} \times \mathrm{P}^{2}\right)
\end{aligned}
$$

$\mathrm{T}$ and $\mathrm{P}$ are the temperature and pressure given in $\mathrm{K}$ and $\mathrm{MPa}$ units, respectively.

\subsection{THE GROWTH RATE OF HYDRATE FORMATION}

The growth rate of hydrate formation be presented using the below equation [Hashemi H.et al.; 2014]: 


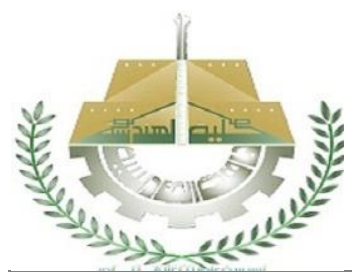

$$
r(t)=-\left.\frac{d n_{R 134 a}}{d t}\right|_{t i}=\left.\frac{\Delta n_{R 134 a}}{\Delta t}\right|_{t i}=\frac{\left(n_{R 134 a, i-1}-n_{R 134 a, i+1}\right)}{\left(t_{i+1}-t_{i-1}\right) * n_{W 0}}
$$

$n_{R 134 a, i-1}$ And $n_{R 134 a, i+1}$ present moles of R134a gas which is hydrate former at $t_{i-1}$ and $t_{i+1}$ respectively. $\mathrm{n}_{\mathrm{w} 0}$ is the initial number of moles of water.

\subsection{THE APPARENT RATE CONSTANT}

The rate of growth of formation forR134a hydrate may be formulated as[Hashemi H.et al.; 2014]:

$$
\mathrm{r}(\mathrm{t})=\frac{d n}{d t}=\mathrm{K}\left(f_{g}^{v}-f_{e q}\right)
$$

At a specific time $t_{i}$, the apparent rate constant is estimated by the expression below:

$$
\mathrm{K}_{\mathrm{app}}=\frac{\mathrm{r}(\mathrm{t})}{\left(f_{g}-\mathrm{feq}\right)_{\mathrm{ti}}}
$$

Which $\mathrm{K}_{\mathrm{app}}$ re0presents the rate constant of hydrate reaction.

\subsection{WATER TO HYDRATE CONVERSION}

The water converts to hydrate for each mole of water feed can be estimated by relation below [Babaee S. et al.; 2015]:

$$
\text { The Water conversion }=\frac{\mathrm{M} \times \Delta \mathrm{n}}{\mathrm{n}_{\mathrm{w} 0}} \times 100 \%
$$

\subsection{THE STORAGE CAPACITY (SC)}

The storage capacity is a volume of gas stored in per volume of hydrate which calculates by following equation (Suradkar,2006):

$$
\mathrm{SC}=\frac{V_{S T P}}{V_{H}}=\frac{\Delta n \times\left(\frac{R \times T_{S T P}}{P_{S T P}}\right)}{V_{H}}
$$

where subscript STP stands for the standard conditions and $\mathrm{V}_{\mathrm{H}}$ is the gas hydrate volume at the end of the reaction, which is calculated by Eq. (12). Figure(5) shows The algorithm of previous calculation for calculating the gas consumed $(\Delta \mathrm{n})$, hydrate growth rate $(\mathrm{r}(\mathrm{t}))$, apparent rate $\left(\mathrm{K}_{\mathrm{app}}\right)$, conversion of water to hydrate, and storage capacity of R-134a gas. 


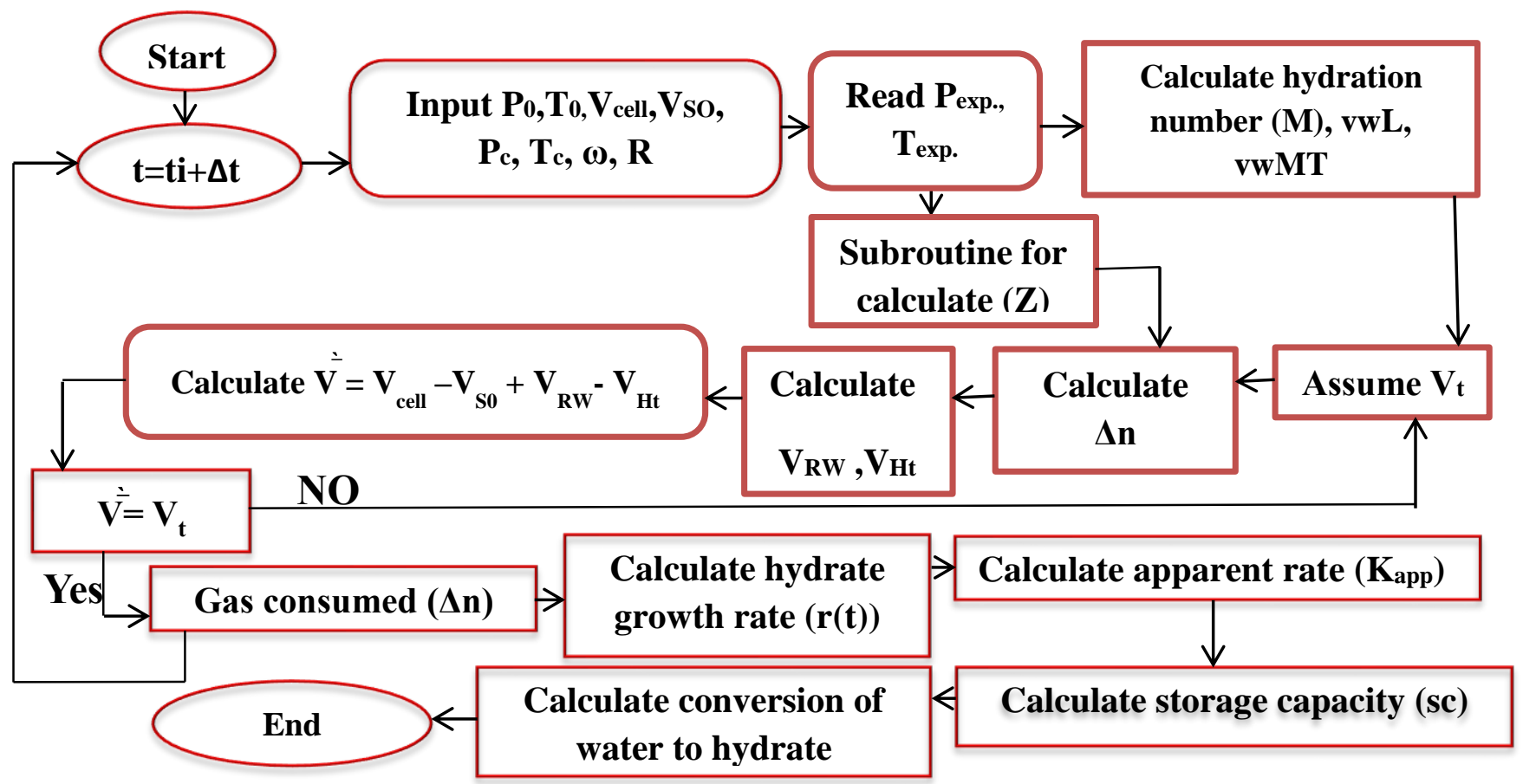

Figure (5): The suggested algorithm to calculate the gas consumed and the apparent rate hydrate formation of R134a.

\section{RESULT AND DISCUSSION}

In the isochoric system, the pressure drop and the variation of gas consumed in the system of pure water , R-134a and in the system of pure water , R-134a and different concentrations for Tween 80 are the resulted from dissolution when gas dissolved in the liquid aqueous phase, the nucleation when the pressure is stable until formation and formation process when hydrate start growth. However, when the hydrate formation growth stops, the pressure is stabilized because of the HFC134a is supersaturated and phase equilibrium has been reached as shown in figure (6a,b,c,d, and e). 


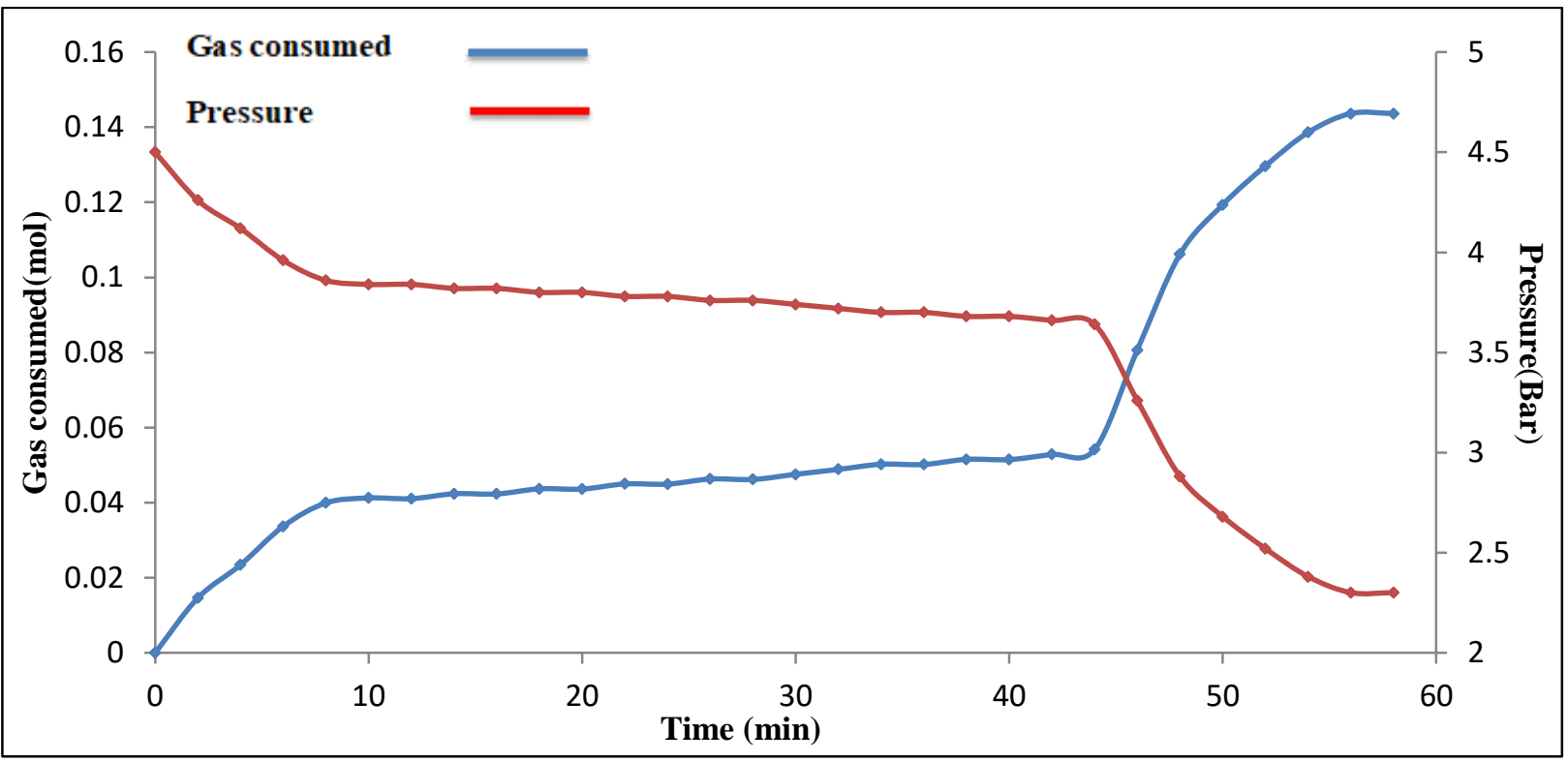

Figure 6a. Pressure-Time-Gas consumed behavior obtained with pure water and (without Tween 80)

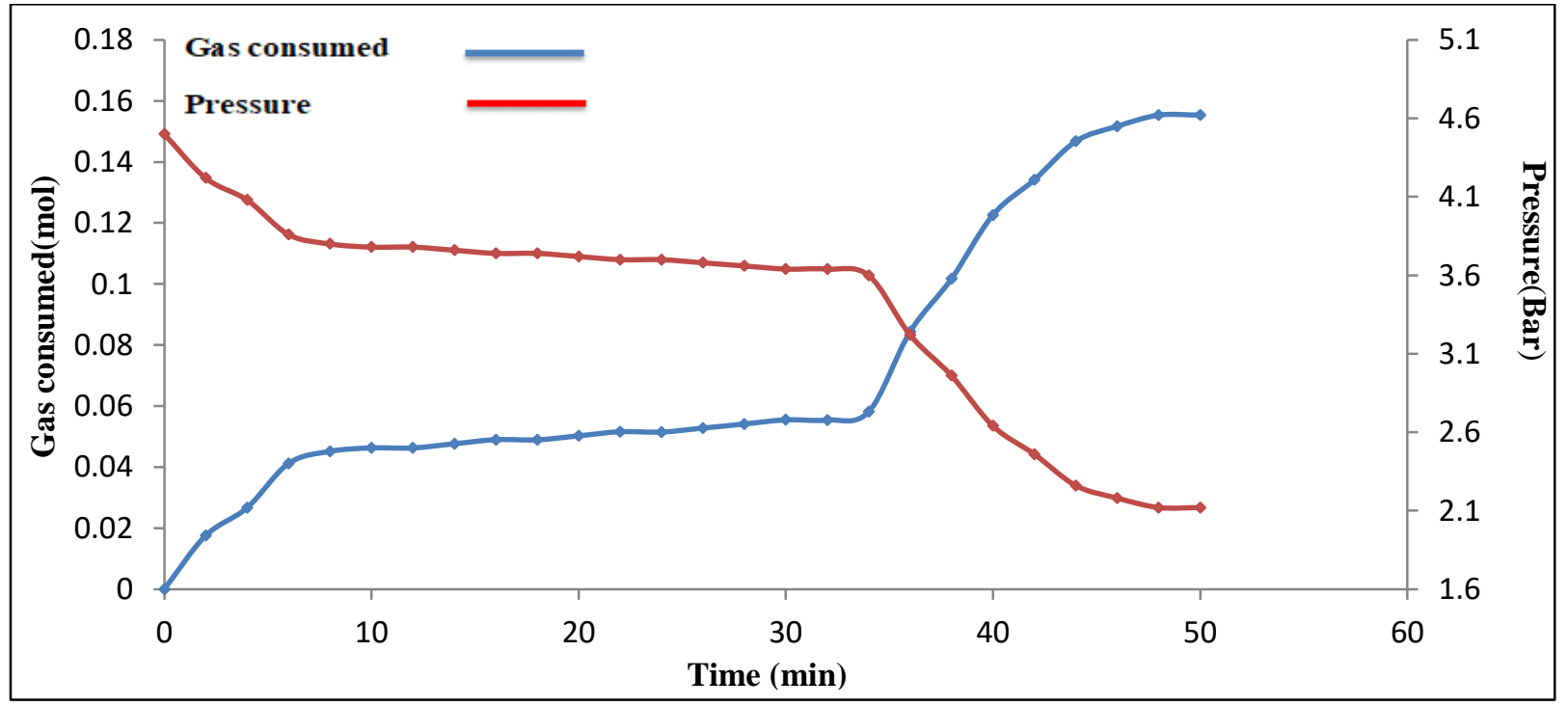


Figure 6b. Pressure-Time-Gas consumed behavior obtained with $25 \mathrm{ppm}$ concentrations of Tween 80

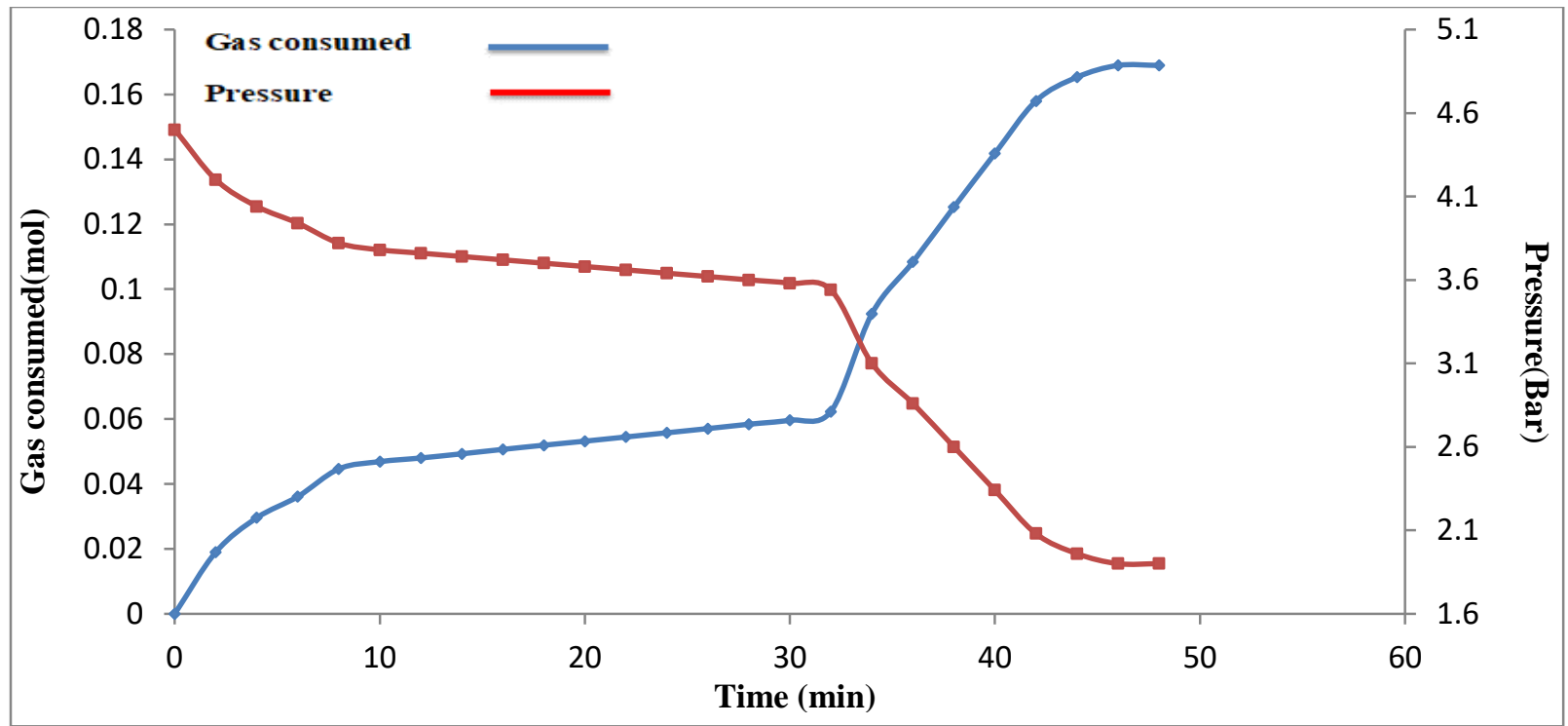

Figure 6c. Pressure-Time-Gas consumed behavior obtained with $50 \mathrm{ppm}$ concentrations of Tween 80

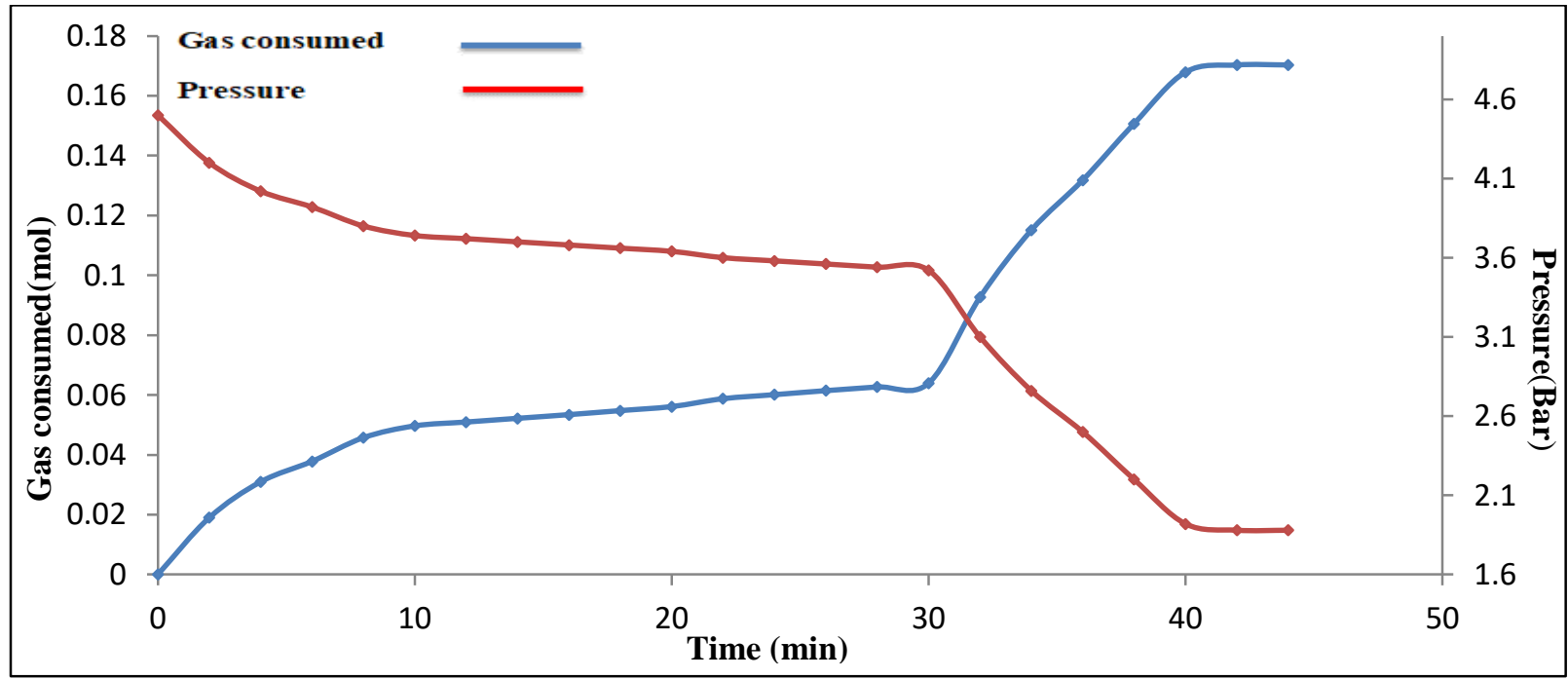

Figure 6d. Pressure-Time-Gas consumed behavior obtained with $75 \mathrm{ppm}$ concentrations of Tween 80 

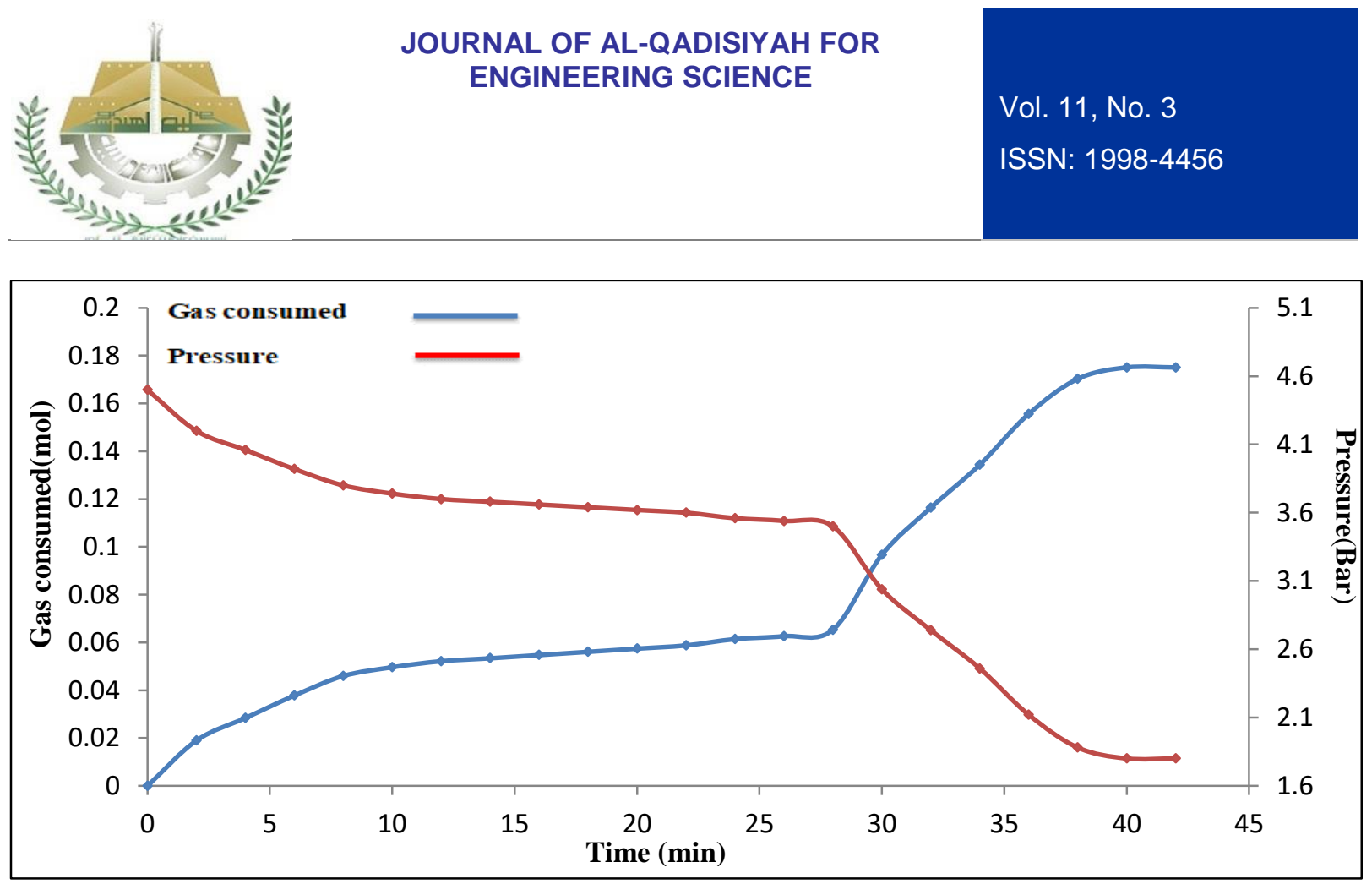

Figure 6e. Pressure-Time-Gas consumed behavior obtained with 100 ppm concentrations of Tween 80

From figure (6a,b,c,d, and e), it can also be seen that when formation region is reached, the gas hydrate forms in pure water is about $48 \mathrm{~min}$, in the water solution with $25 \mathrm{ppm}$ of Tween 80 in about $40 \mathrm{~min}$, in the concentration of $50 \mathrm{ppm}$ about $38 \mathrm{~min}$, in the concentration of $75 \mathrm{ppm}$ about $36 \mathrm{~min}$ and in the concentration of $100 \mathrm{ppm}$ about $32 \mathrm{~min}$. Hence, the formation process of HFC134a hydrate is shorted with increasing mass fraction of surfactant Tween 80 in the water solution. Due to the low solubility of gas in water, hydrates appear on the water front in the pure water system. Hydrates also cover the water interface which prevents further water conversion to hydrates, even when stirred due to the low water density compared to water is applied in figure(7). 

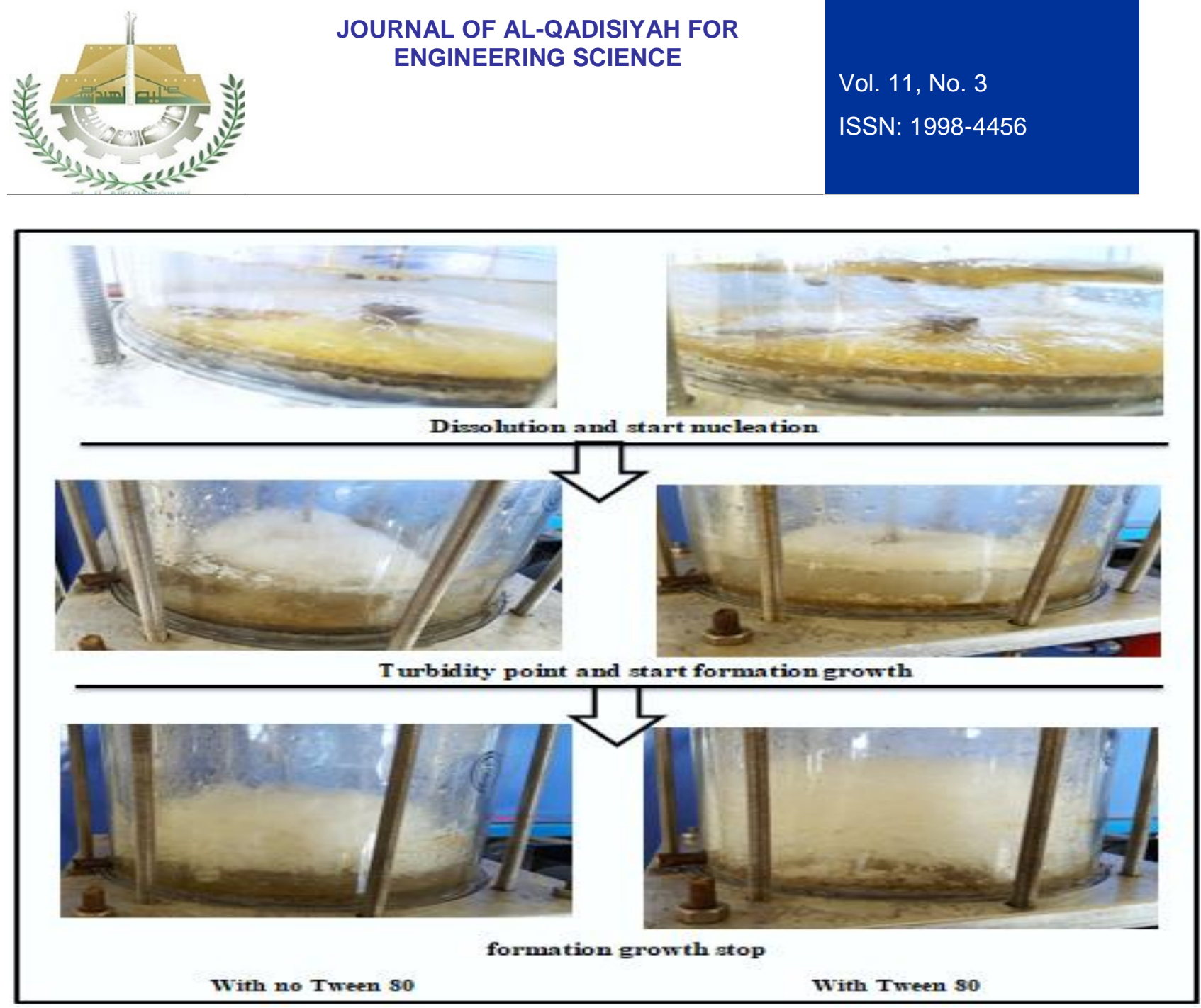

Figure. 7. gas hydrates presenting out in the cell with different concentration of Tween 80 .

By Eq. (2), Figure (8) In comparison with the gas consumed in the pure water system with the presence of the surfactant in various concentrations 25, 50, 75 and $100 \mathrm{ppm}$, when increase the surfactant concentration, the gas consumed amount increases and the formation of hydrates increases. As shown in Fig. 8 maximum gas consumed amount was achieved at a surfactant concentration of $100 \mathrm{ppm}$ and the steady state of hydrate is realized in about 42 minutes and the induction time is shortest figure (9). 


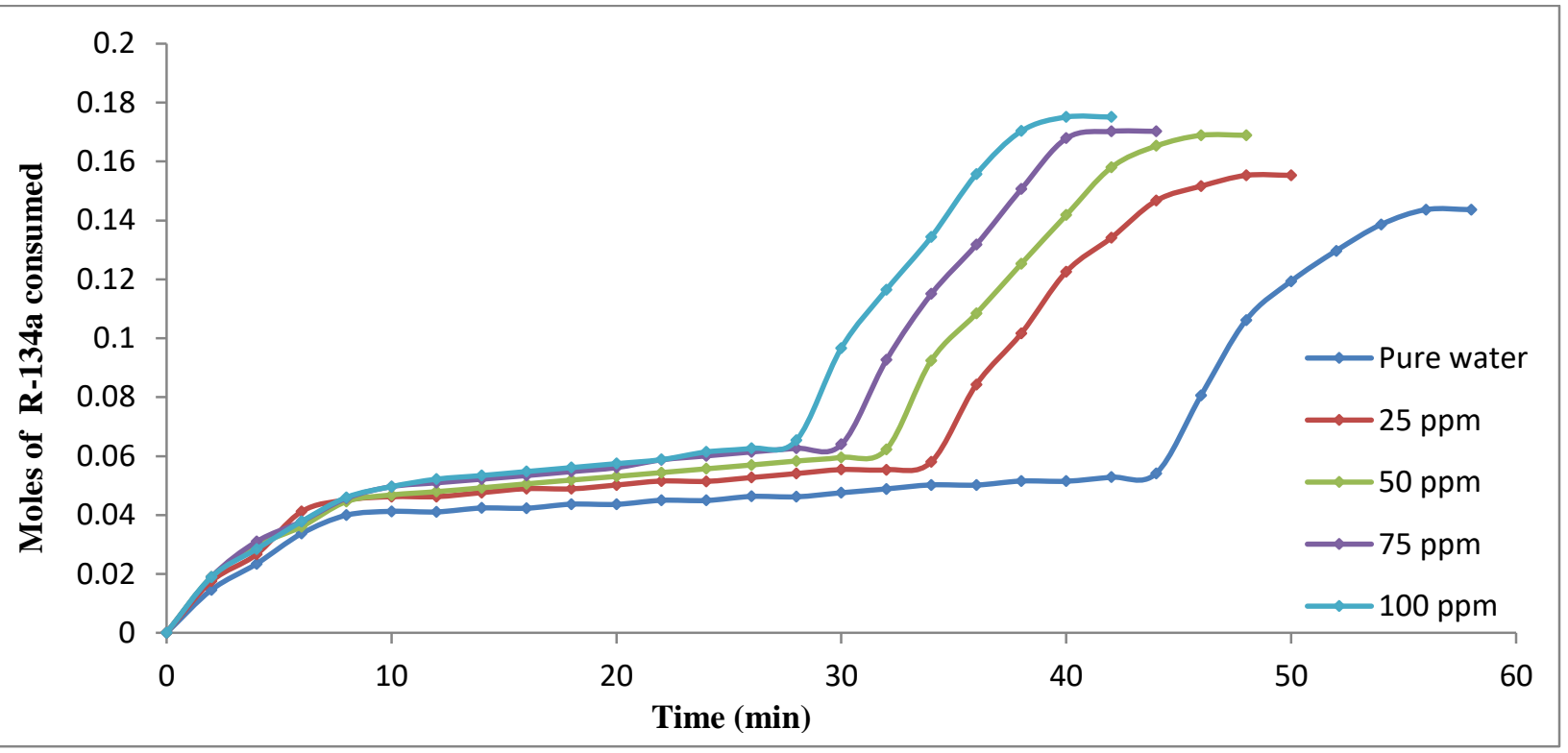

Figure.8. Refrigerant gas (R-134a) mole consumed without and with different concentrations of Tween 80.

Induction time at 50 and $25 \mathrm{ppm}$ is 26 and $30 \mathrm{~min}$ respectively. At $75 \mathrm{ppm}$ the hydrate attains a steady state in about 44 minutes and the induction time is 24 min which is longer than that of 100 ppm.

As figure (10) shows, surfactant promoter increase the gas hydrate storage capacity of. 0.0863 mole is the maximum gas amount in hydrate and $60 \mathrm{~V} / \mathrm{V}$ is the maximum storage capacity of hydrate at standard condition.

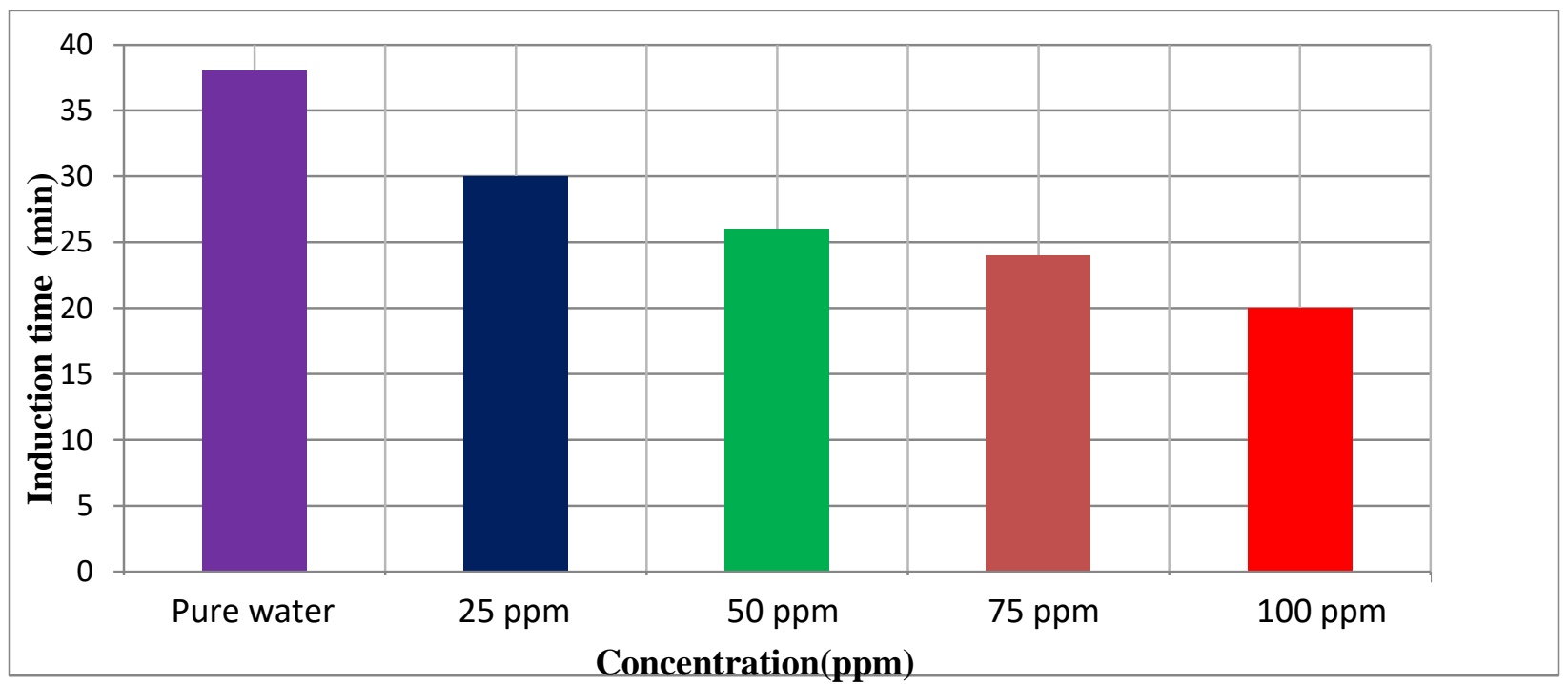


Figure. 9. Compare the induction time of pure water agents different concentration of surfactant Tween 80 .

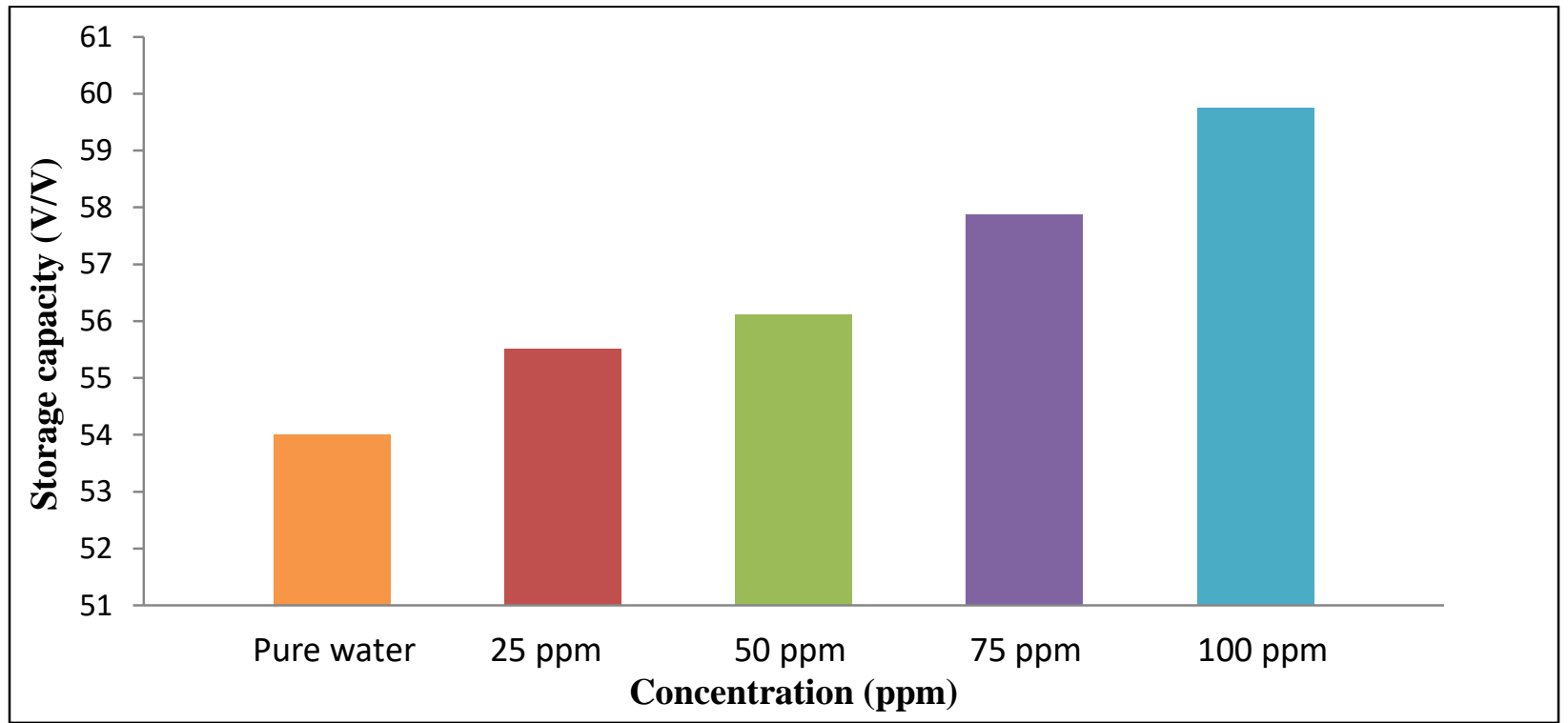

Figure.10. Compare the pure water storage capacity with and without different concentration of surfactant Tween 80 .

The water moles convert to hydrate during the hydrate growth process was calculated for the binary system and ternary system. Figure (11) shows the water conversion increased due to gas consumed because of increasing in the driving force with time.

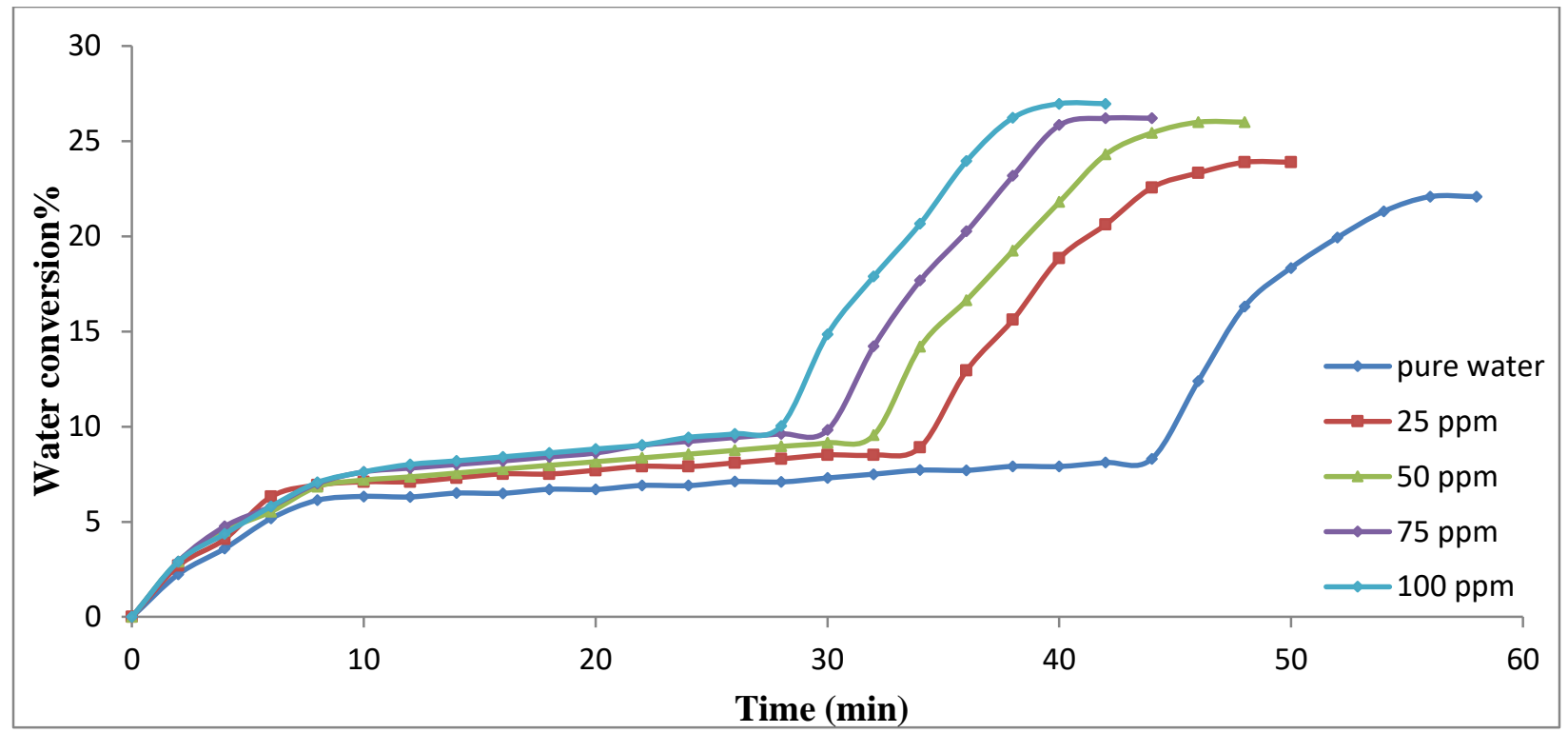

\section{Page 388}

Copyright (c) 2018 Al-Qadisiyah Journal For Enginnering Science. All rights reserved. 


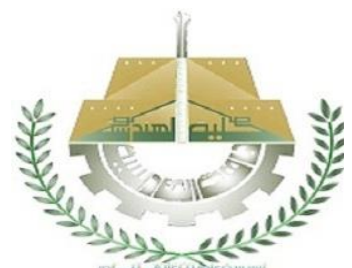

Figure (11): The water to hydrate conversion as faction with time at different concentrations of Tween 80

Hydrate growth represented in the figure (12a,b,c,d, and e) for different concentration of Tween 80.The growth rate in the presence Tween 80 for ternary system increases gradually until reaching the maximum value at 18 minutes in 50ppm Tween 80 . The rates of growth reduce when time increases, because of the drooping in the driving force with time. As a result of the use of the surfactant, the solubility of the gas increases in the water, causing an increase in the particles of the micro hydrates and thus generates a higher surface area by reducing the contact angle and thus a higher mass transfer rate. The fluctuation in the growth rate is the result of passing through different stages from the beginning of the gas dissolving through the stage of nucleation until it reaches the stage of growth accompanied by a rapid drop in pressure and this can be seen through the bends. The surfactant is one of the effective anti-agglomerates that prevent agglomeration of hydrate crystals that causing less free water to entrap between solid hydrates.

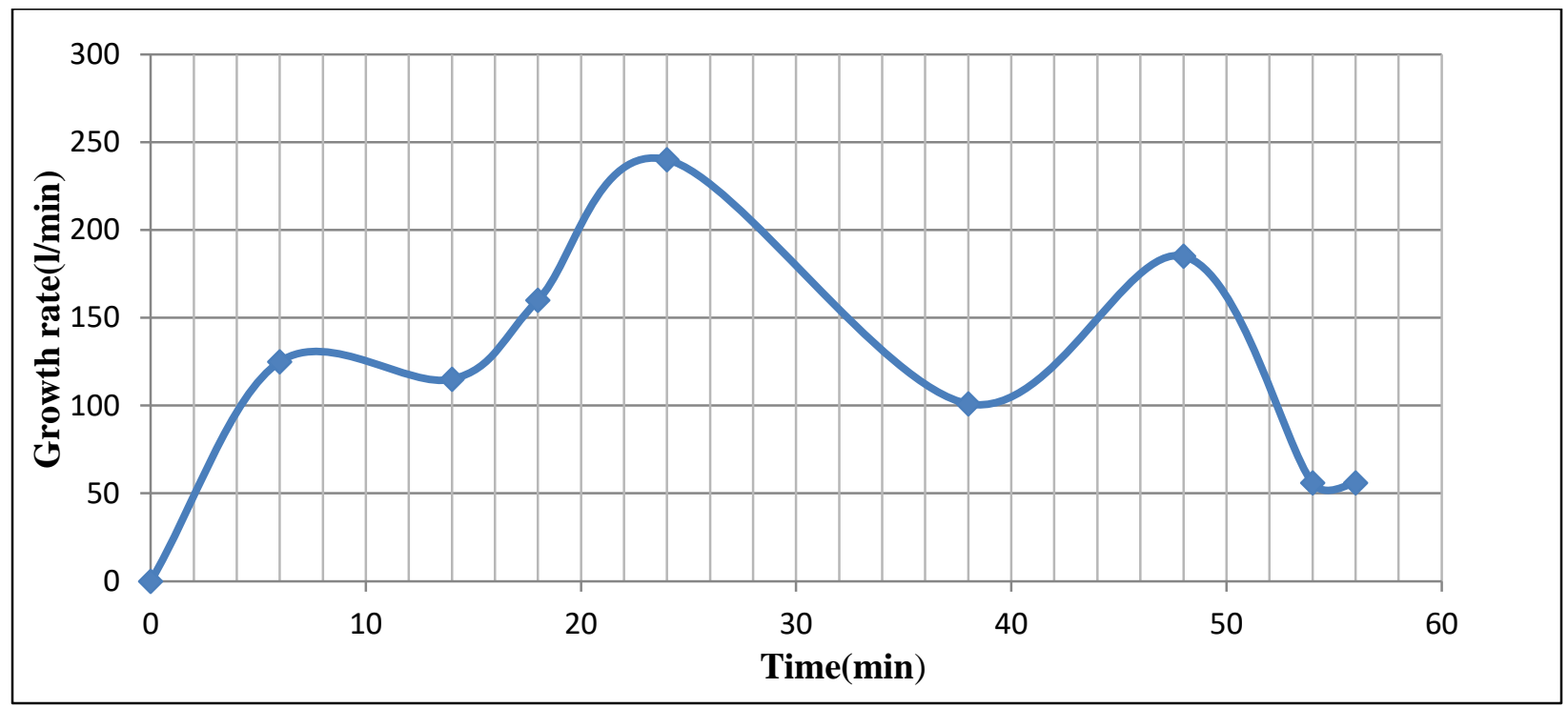

Figure (12a): The R134a hydrate growth rate against time without Tween 80 . 


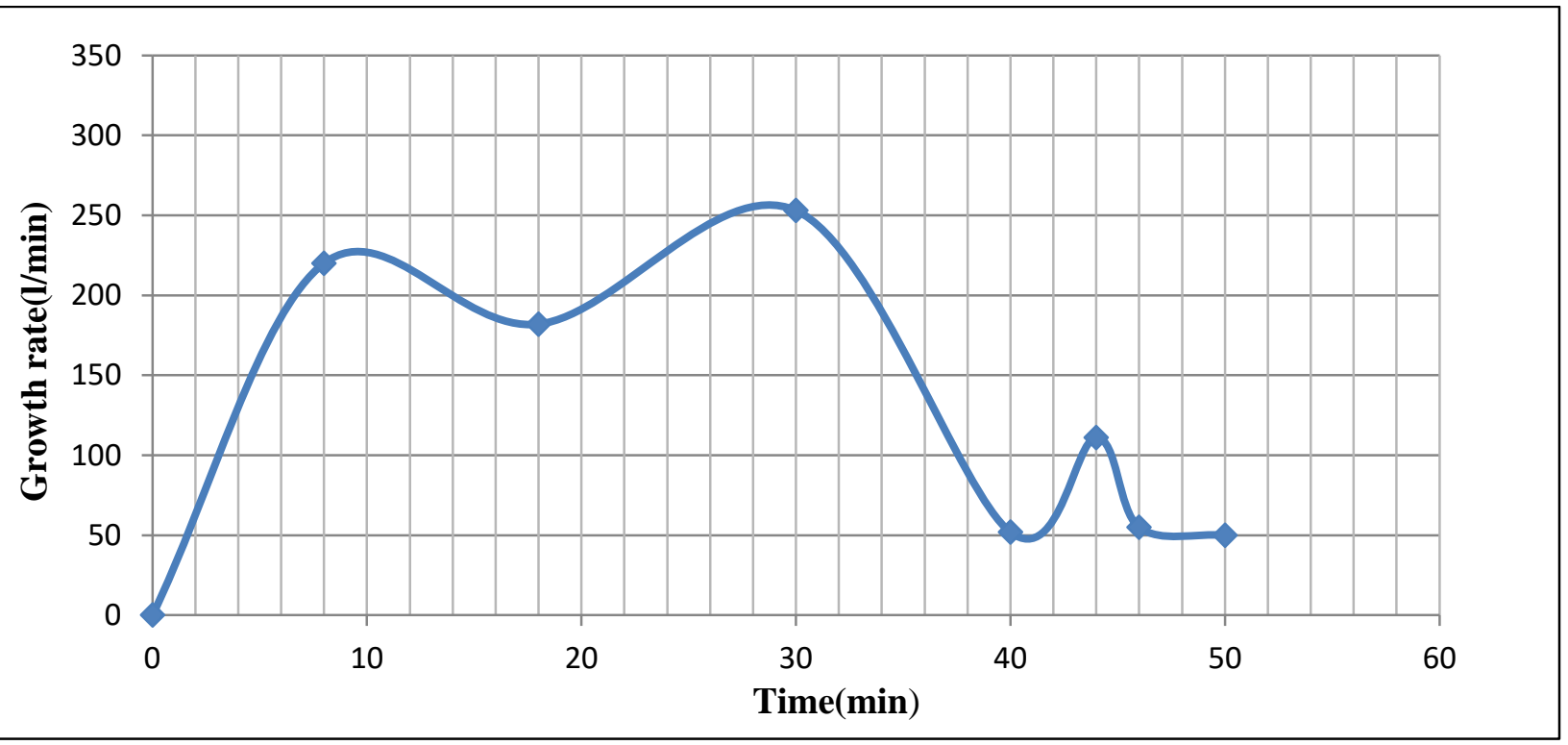

Figure (12b): The R134a hydrate growth rate against time with $25 \mathrm{ppm}$ of Tween80

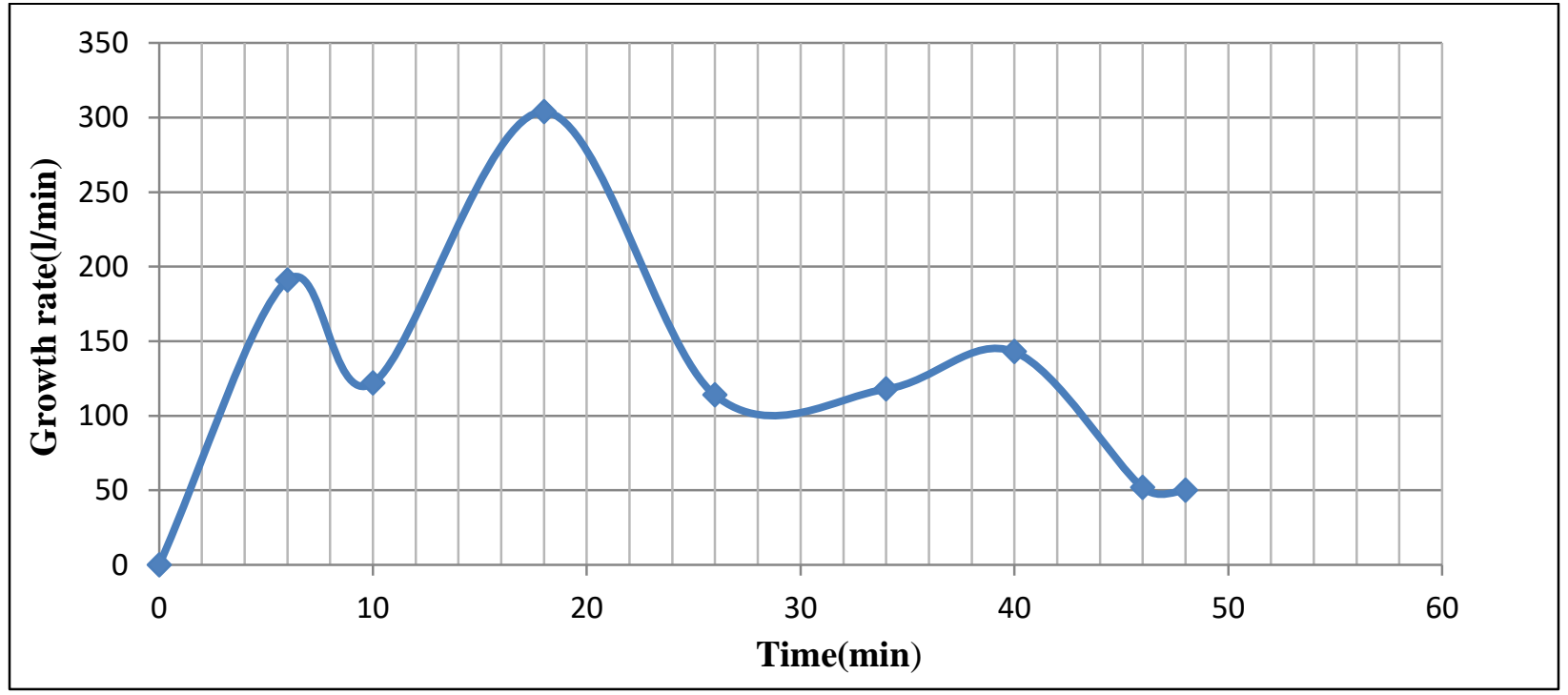

Figure (12c): The R134a hydrate growth rate against time with $50 \mathrm{ppm}$ of Tween 80 


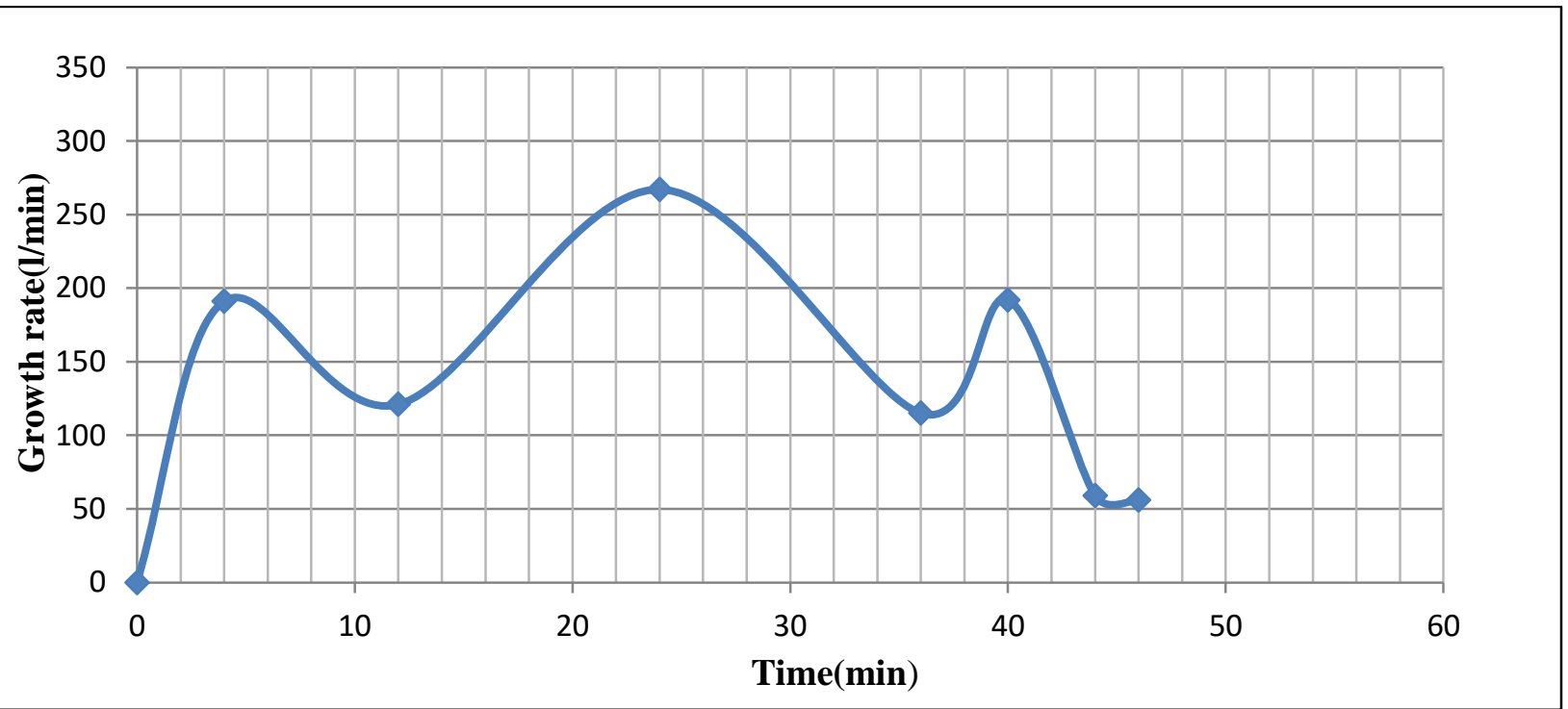

Figure (12d): The R134a hydrate growth rate against time with 75 ppm of Tween80

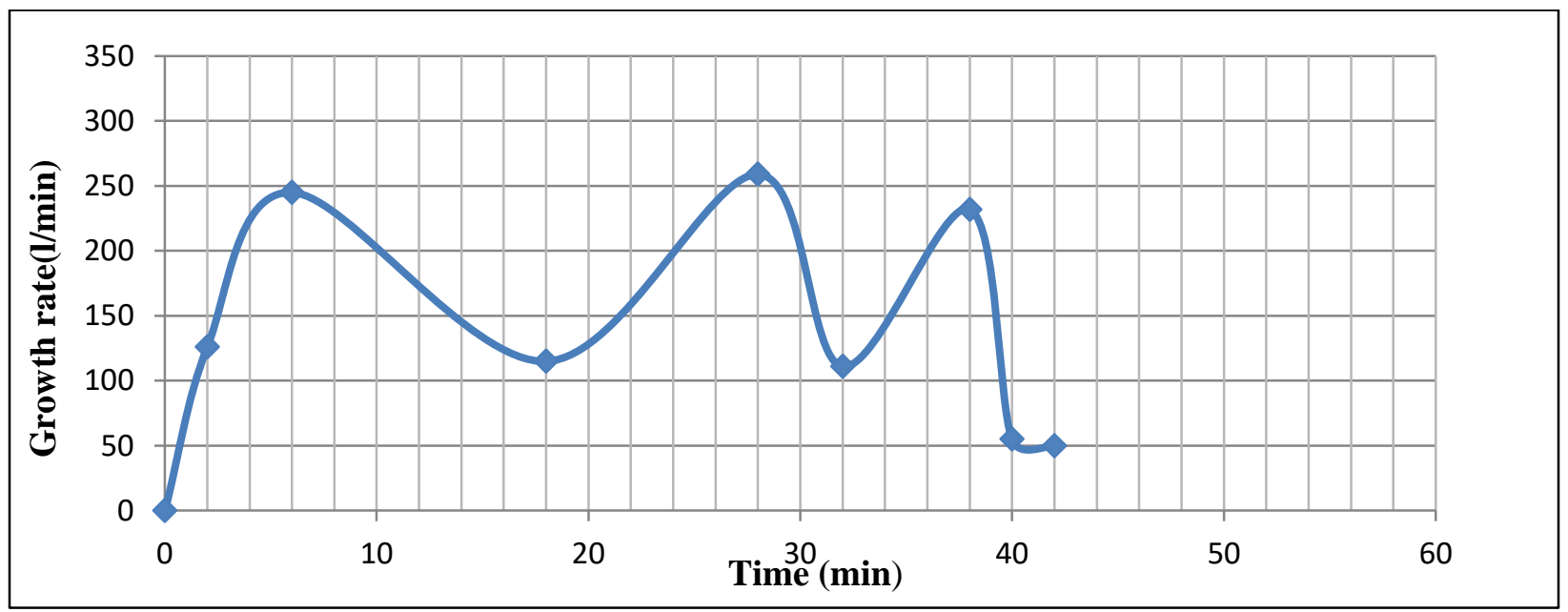

Figure (12e): The R134a hydrate growth rate against time with $100 \mathrm{ppm}$ of Tween 80

During hydrate nucleation and growth, the apparent rate constant reduces quickly to a constant value then the formation of hydrate is completed. In figure (13) notice the general behavior of $\mathrm{K}_{\text {app }}$ is the apparent rate decreases with time and that can be explained when hydrate formed the heat increase due to this phenomena is exothermic that cause the rate to decrease. 

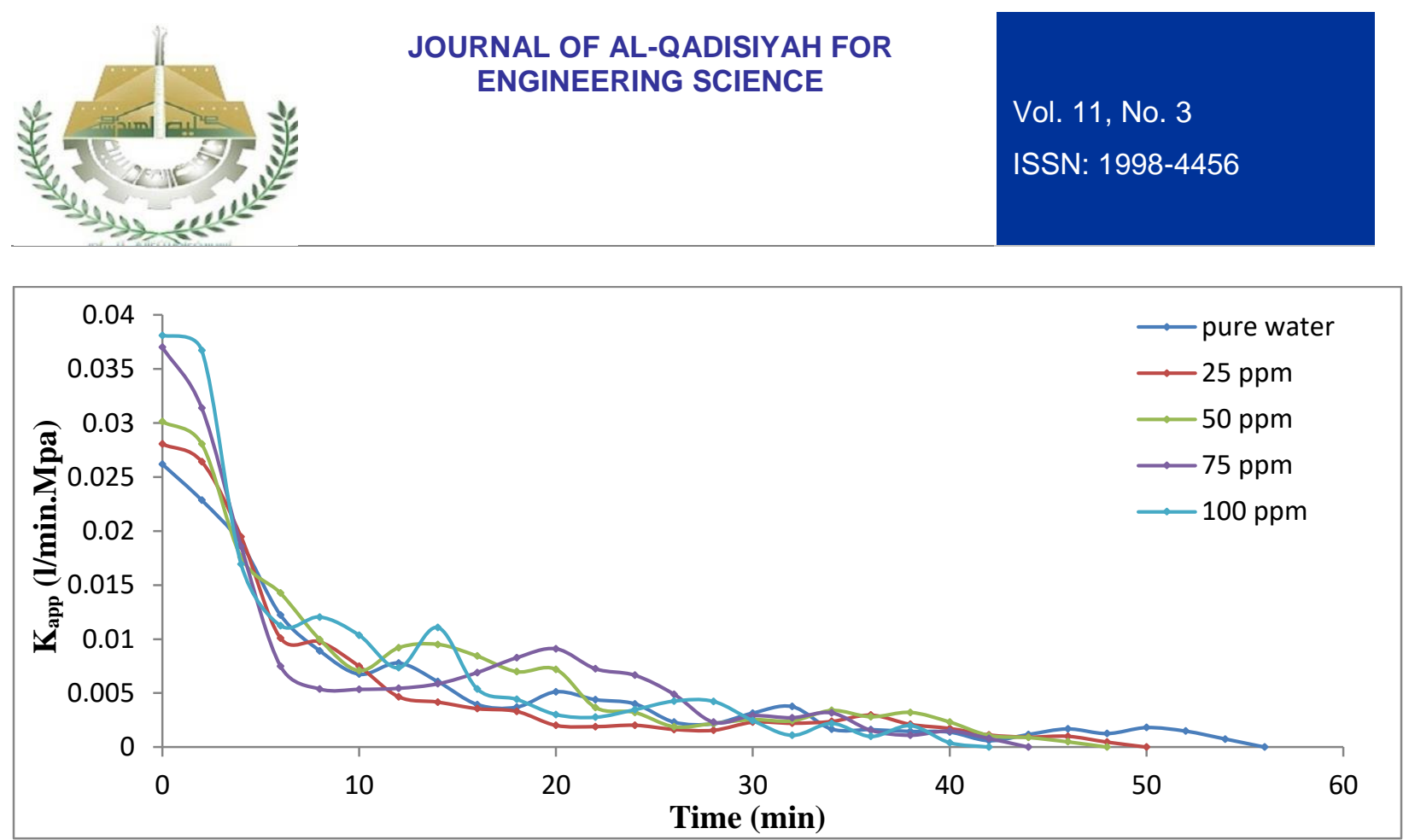

Figure (13): Apparent constant versus time during the growth of R143a hydrate at different concentration of Tween 80 .

\section{CONCLUSIONS}

The effect of the different concentration of the surfactant on the gas hydrates formation of R-134a was observed in terms of improved nucleation of hydrate and hydrate growth rate. The presence of surfactants improves the gas solubility and its spread in the water effectively, as well as to reduce the contact angle and improve contact with the gas-water, which in turn positively affects the rate of formation of hydrates. After using different concentrations of the surfactant 25, 50, 75 and $100 \mathrm{ppm}$, the following conclusions were reached:

(1) In general, Tween 80 at different concentrations (25, 50, 75 and $100 \mathrm{ppm})$ promotes the formation of R-134a gas hydrates effectively.

(2) The maximum effect of Tween 80 on the induction time of R-134a gas hydrates can be achieved at a concentration of $100 \mathrm{ppm}$.

(3)Maximum promotion effect of Tween 80 on R-134a hydrate growth rate was achieved at the concentration of $50 \mathrm{ppm}$.

(4)Maximum theoretical value of storage capacity is $59.75 \mathrm{~V} / \mathrm{V}$ at standard condition that is achieved at a concentration of $100 \mathrm{ppm}$ of Tween 80 .

Gas separation process in hydrate form increases due to increased hydrate nucleation and increased hydrate growth. Desalination, storage and transport have benefited greatly from improved hydrate formation kinetics. 


\section{REFERENCES}

1. Al-Muktar, R.S., Al-Hemeri, S.T., Mahmood, L.W., 2018.Study the dissociation enthalpies for R-134a clathrate hydrate in binary and ternary system. Al-Khuarzmi Engineering Journal.(under publishing).

2.Cassandra Petticrew, 2014. An Investigation into the use of fluorinated Hydrating agents in the desalination of Industrial Wastewater. Chemical Engineering Thermodynamic Stability Conditions of Clathrate Hydrates for Refrigerant (R134a or R410a or R507) with MgCl2 Aqueous Solution, University of KwaZulu-Natal, Durban, South Africa,

3.Clarke, M.A., and Bishnoi, P.R., 2001. Measuring and modeling the rate of decomposition of gas hydrates formed from mixtures of methane and ethane. Chemical Engineering Science, 56(16), pp.4715-4724.

4.Fuhrhop, J.H. and Koning, J., 2007. Membranes and molecular assemblies: the synkinetic approach. Royal Society of Chemistry.

5.Guo, Y., Fan, S., Guo, K. and Chen, Y., 2002, May. The storage capacity of methane in hydrate using calcium hypochlorite as additive. In Mori. 4th International Conference on Gas Hydrates. Yokohama (Vol. 1040).

6.Han, X., Wang, S., Chen, X. and Liu, F., 2002, May. Surfactant accelerates gas hydrate formation. In 4th International Conference on Gas Hydrates, Yokohama, Japan (pp. 1036-1039).

7.Kalogerakis, N., Jamaluddin, A.K.M., Dholabhai, P.D. and Bishnoi, P.R., 1993, January. Effect of surfactants on hydrate formation kinetics. In SPE international symposium on oilfield chemistry. Society of Petroleum Engineers.

8.Klauda, J.B., and Sandler, S.I., 2000. A fugacity model for gas hydrate phase equilibria. Industrial \& engineering chemistry research, 39(9), pp.3377-3386.

9.Kumar, A., Sakpal, T., Linga, P. and Kumar, R., 2013. Influence of contact medium and surfactants on carbon dioxide clathrate hydrate kinetics. Fuel, 105, pp.664-671. 


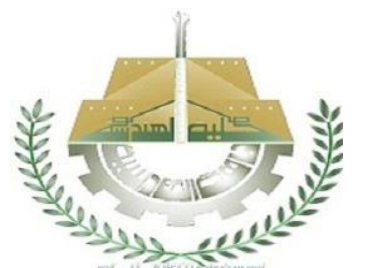

10.Kumar, A., Sakpal, T., Linga, P. and Kumar, R., 2015. Enhanced carbon dioxide hydrate formation kinetics in a fixed bed reactor filled with metallic packing. Chemical Engineering Science, 122, pp.78-85.

11. Leporcher, E.M., Peytavy, J.L., Mollier, Y., Sjoblom, J. and Labes-Carrier, C., 1998, January. Multiphase transportation: hydrate plugging prevention through crude oil natural surfactants. In SPE Annual Technical Conference and Exhibition. Society of Petroleum Engineers.

12.Lim, Y. A.; Babu, P.; Kumar, R.; Linga, P. Morphology of carbon dioxide-hydrogencyclopentane hydrates with or without sodium dodecyl sulfate. Cryst. Growth Des. 2013, 13, 2059.

13.Mohammadi, A.H., Eslamimanesh, A., Belandria, V., Richon, D., Naidoo, P., Ramju-gernath, D.,2012.Phase equilibrium measurements for semi-clathrate hydrates of the $(\mathrm{CO} 2+\mathrm{N} 2+$ tetra-nbutyl ammonium bromide) aqueous solution system .J. Chem. Thermodyn.46,57-61

14.Munck, J., Skjold-Jørgensen, S. and Rasmussen, P., 1988. Computations of the formation of gas hydrates. Chemical Engineering Science, 43(10), pp.2661-2672.

15.Ngema, P.T., Naidoo, P., Mohammadi, A.H., Richon, D. and Ramjugernath, D., 2016. Thermodynamic stability conditions of clathrate hydrates for refrigerant (R134a or R410a or R507) with a $\mathrm{MgCl}_{2}$ aqueous solution. Fluid Phase Equilibria, 413, pp.92-98.

16.Peng, D.Y. and Robinson, D.B., 1976. A new two-constant equation of state. Industrial \& Engineering Chemistry Fundamentals, 15(1), pp.59-64.

17.Sabil, K.M., 2009. Phase behavior, thermodynamics and kinetics of clathrate hydrate systems of carbon dioxide in presence of tetrahydrofuran and electrolytes. Diss. Ph. D. dissertation, Technische Universiteit Delft, Delft, Holanda.

18.Shah, D.O., 1977. The world of surface science. Chemical Engineering Education, pp.14-48.

19.Sloan ED. The clathrate hydrate of natural gases. 3rd ed. New York: Marcel Dekker Inc.; 2008.

20.Smith, J.M., Van ness, HC, Abbott, MW, 2001. Introduction to Chemical Engineering Thermodynamics. 


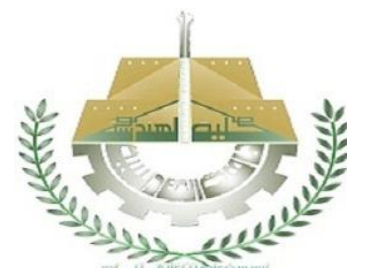

21.Sum, A.K., Koh, C.A. and Sloan, E.D., 2009. Clathrate hydrates: from laboratory science to engineering practice. Industrial \& Engineering Chemistry Research, 48(16), pp.7457-7465.

22.Sun, Q., Guo, X., Liu, A., Liu, B., Huo, Y. and Chen, G., 2010. Experimental study on the separation of $\mathrm{CH} 4$ and N2 via hydrate formation in TBAB solution. Industrial \& Engineering Chemistry Research, 50(4), pp.2284-2288.

23.Suradkar, Y.R. and Bhagwat, S.S., 2006. CMC determination of an odd carbon chain surfactant (C13E20) mixed with other surfactants using a spectrophotometric technique. Journal of Chemical \& Engineering Data, 51(6), pp.2026-2031.

24.Torré, J.P., Dicharry, C., Ricaurte, M., Daniel-David, D. and Broseta, D., 2011. CO2 capture by hydrate formation in quiescent conditions: in search of efficient kinetic additives. Energy Procedia, 4, pp.621-628.

25. Zhang, B.Y., Qiang, W. and Sun, D.L., 2008. Effect of surfactant Tween on induction time of gas hydrate formation. Journal of China University of Mining and Technology, 18(1), pp.18-21.

26.Zhang, H., Yao, M., Morrison, R.A., and Chong, S., 2003. Commonly used surfactant, Tween 80, improves absorption of P-glycoprotein substrate, digoxin, in rats. Archives of Pharmacal Research, 26(9), pp.768-772.

27.Zhong, Y. and Rogers, R.E., 2000. Surfactant effects on gas hydrate formation. Chemical Engineering Science, 55(19), pp.4175-4187. 